\title{
POSTCHARGE MENTAL HEALTH DIVERSION: CHARACTERISTICS OF CLIENTS AND PREDICTORS OF SUCCESS
}

\author{
Sonya Basarke \\ Master of Arts, Ryerson University, 2010 \\ Honours Bachelor of Science, University of Toronto at Scarborough, 2007 \\ Dissertation presented to Ryerson University \\ in partial fulfillment of the requirements for the degree of \\ Doctor of Philosophy \\ in the Program of \\ Psychology
}

Toronto, Ontario, Canada, 2014

CSonya Basarke 2014 
I hereby declare that I am the sole author of this dissertation. This is a true copy of the dissertation, including any required final revisions, as accepted by my examiners.

I authorize Ryerson University to lend this dissertation to other institutions or individuals for the purpose of scholarly research

I further authorize Ryerson University to reproduce this dissertation by photocopying or by other means, in total or in part, at the request of other institutions or individuals for the purpose of scholarly research.

I understand that my dissertation may be made electronically available to the public. 
Postcharge Mental Health Diversion: Characteristics of Clients and Predictors of Success

Sonya Basarke

Doctor of Philosophy in the program of Psychology, 2014

Ryerson University

\begin{abstract}
How to best serve criminal offenders who have mental health issues is of ongoing concern within the justice system in Canada. Mental health diversion has become a popular option that allows mentally disordered offenders to be diverted from custodial sentences to community treatment and supports. However, research on this type of intervention, particularly in Canada, is scant. In order to address this gap, the current set of studies examined mental health diversion in a multisite sample obtained from court support programs in the Greater Toronto Area. In Study 1, it was found that individuals who successfully completed their diversion programming were less likely to have a criminal history and had fewer clinical and psychosocial issues. These results were borne out in the multivariate analyses in Studies 2 and 3 as well, with individuals who had a criminal history, more clinical needs, and who committed more severe nonviolent index offences having lower odds of successfully completing their diversions. In Study 4, when these predictors were developed into a screening tool to determine the likelihood of diversion success, they still predicted diversion outcome at better than chance levels, but the overall predictive accuracy was lower than that found in the multivariate models from Study 3.
\end{abstract}




\section{Acknowledgements}

The completion of my graduate schooling and this dissertation was a group effort. There are a number of amazing people who helped me through all the bumps in my road to becoming a psychologist. First, a huge thank you to my "dream team” of supervisors: Dr. John Turtle and Dr. Michael Seto. I am so grateful for how generously you shared your expertise, support, and your time over the many years we have worked together. Thank you to Dr. Frank Sirotich for facilitating the use of the diversion data for my dissertation, and also for your endless patience with all my questions. Thank you to Dr. Alasdair Goodwill for all your work on my dissertation committee, and your help with my statistical conundrums. Thank you dad and mom for all your support and help...in graduate school and in life. I would not have finished this degree without it, or without Mare-Bear's editing. Thank you to Sean "what's for dinner?" Basarke, mostly so you can see your name on a dissertation...ouch! I went there. Just kidding. You know how you contributed to this degree, so thank you. But you still need to call me "Doctor." Mario, you worked two jobs so I could finish school, and are always the sunshine in my life. Thank you. But you also need to call me "Doctor." Bonnie "shopping is cheaper than therapy" Cheng, thank you for all the years of Tim Horton's trouble-shooting sessions! Finally, a shoutout to my Meggie, who kept me company for my hours and hours of writing. 


\section{Table of Contents}

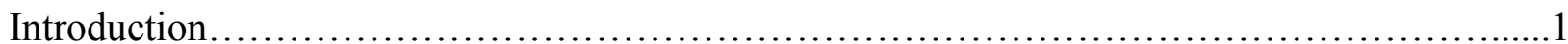

Diversion Effectiveness .........................................................

Questions Remaining about Diversion Programming...............................9

Predictors of Outcome from Diversion Literature................................10

Relevant Nondiversion Literature on Potential Predictors.............................18

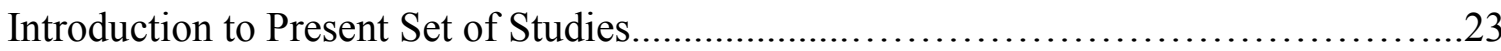

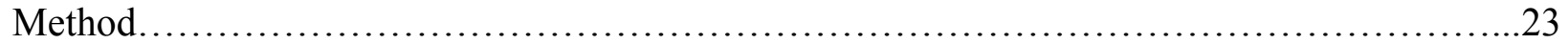

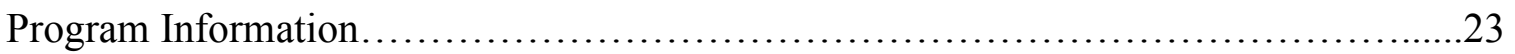

Mental Health Court Support Consortium Diversion Procedure.............................24

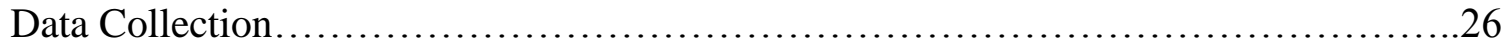

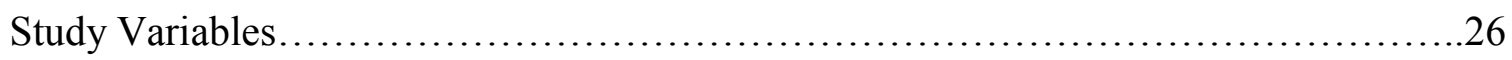

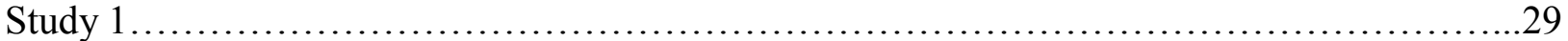

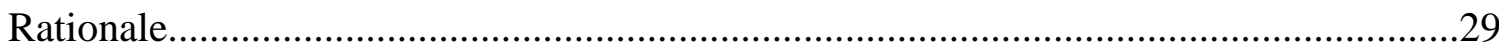

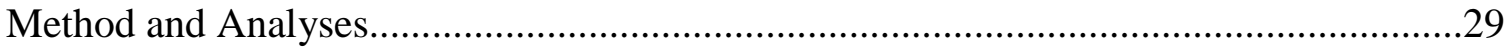

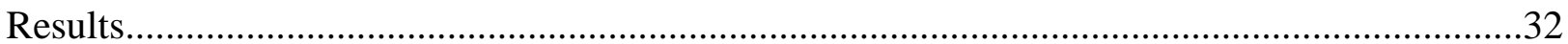

Univariate Results: Overall Sample......................................................................... 32

Univariate Relationships: All Variables and Diversion Outcome......................................33

Univariate Relationships: All Variables and Criminal History...........................................34

Univariate Relationships: All Variables and Reason for Unsuccessful Diversion.............35

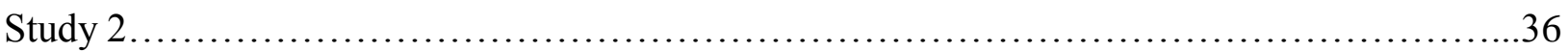

Rationale

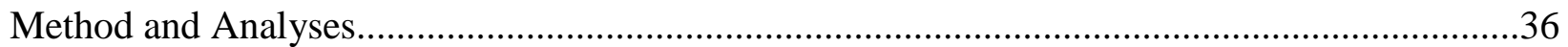


Results.

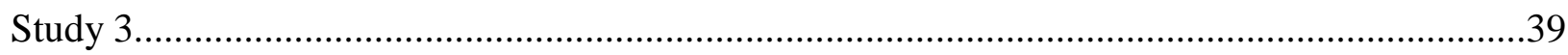

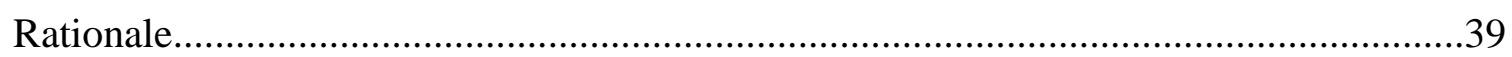

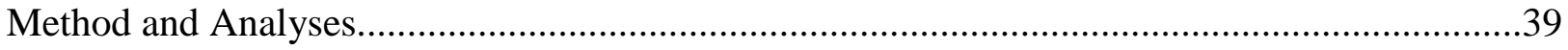

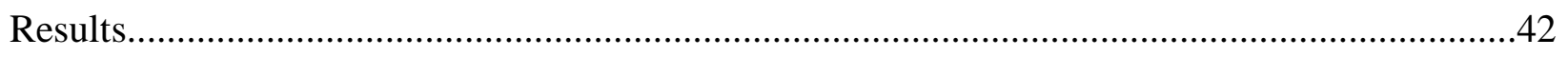

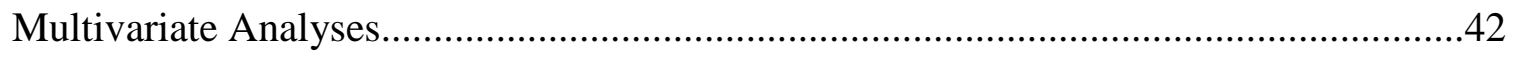

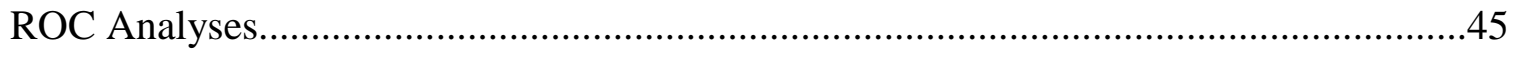

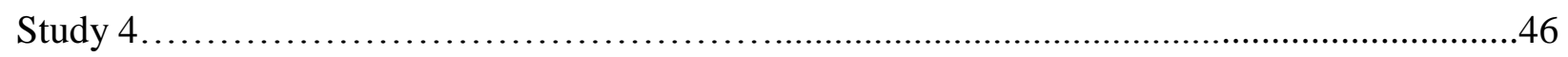

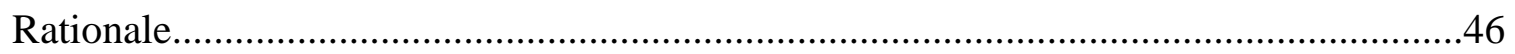

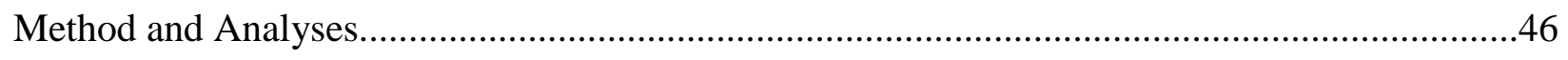

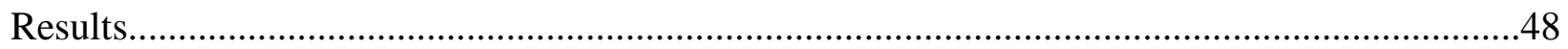

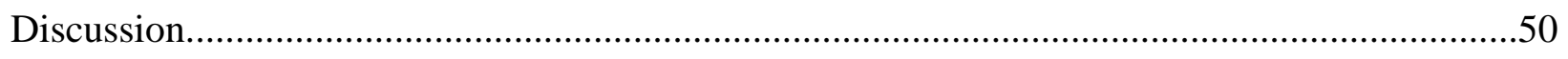

Who are the Successful and Unsuccessful Divertees?............................................50

What are the Predictors of Diversion Success? ..................................................52

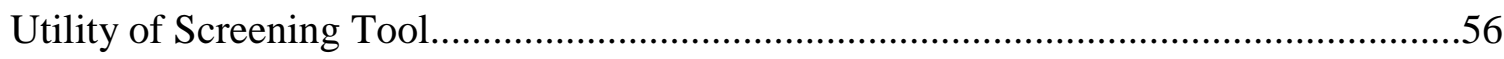

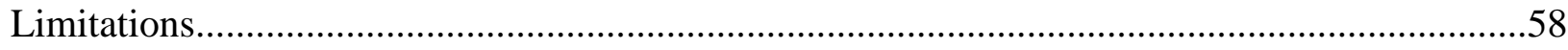

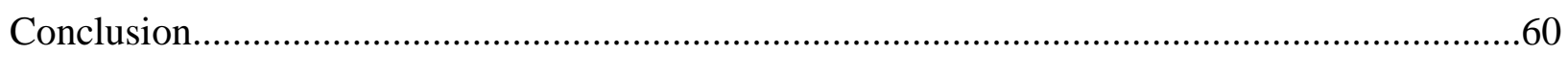

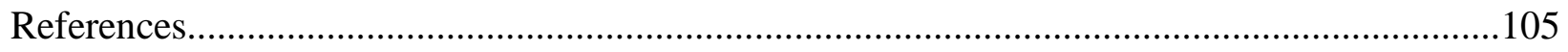




\section{List of Tables}

Table 1. Operational Definitions of All Variables ..................................................................61

Table 2. Univariate Relationships: Known/Unknown Criminal History...................................70

Table 3. Univariate Relationships: Diversion Outcome.....................................................74

Table 4. Univariate Relationships: Criminal History....................................................... 78

Table 5. Univariate Relationships: Reason for Unsuccessful Diversion.................................82

Table 6. Forced Entry Multivariate Analysis .................................................................86

Table 7. Stepwise Multivariate Analyses: Model 1............................................................8

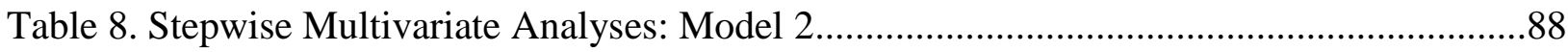

Table 9. Stepwise Multivariate Analyses: Model 3.........................................................89

Table 10. Stepwise Multivariate Analyses: Model 4 .........................................................90

Table 11. Area Under the Curve Statistics: All Models...................................................91

Table 12. Intercorrelations for Checklist Items......................................................... 92

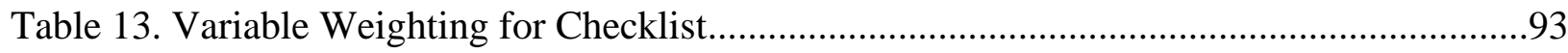

Table 14. Area Under the Curve Statistics: Checklist Construction Sample..............................94

Table 15. Area Under the Curve Statistics: Checklist Reliability Sample...............................95

Table 16. Probability Distribution: Checklist Construction Sample.......................................96

Table 17. Probability Distribution: Checklist Reliability Sample.........................................97

Table 18. Probability Distribution: Collapsed Categories, Construction Sample.......................98

Table 19. Probability Distribution: Collapsed Categories, Reliability Sample...........................99 


\section{List of Appendices}

Appendix. Detailed Variable Categories............................................................................... 100 


\section{Postcharge Mental Health Diversion: Characteristics of Clients and Predictors of Success}

An important issue faced by policy makers and front-line workers within the legal system is how to best balance the unique needs of offenders with mental health issues with consideration for public safety. One reason for concern is that individuals with mental illness are at increased risk of police contact and arrest. For example, research conducted with an Ontario sample obtained from police data containing information on individuals who have had some type of contact with police (Hartford, Heslop, Stitt, \& Hoch, 2005) has shown that individuals with mental illness were up to three times more likely to have any type of contact with the police, and were more likely to be arrested or charged with a crime within a one-year period, compared to individuals without mental illness (51\% vs. 31\%, respectively). Furthermore, in 2009 in Canada, it was reported that $11 \%$ of federal offenders have a mental disorder diagnosis at the time of admission to prison (Public Safety Canada, 2009). This proportion is even larger in female offenders, with women being twice as likely as men to have a mental disorder diagnosis at admission. Statistics indicate that these numbers are increasing over time, which suggests that novel solutions need to be examined in order to curb the rates at which individuals with mental illness are dealt with in the criminal justice system, consistent with the principle that mentally disordered individuals are better served by mental health and social service systems. The first Mental Health Strategy for Canada underscores the importance of this issue, identifying the need to "reduce the over-representation of people living with mental health problems and illness in the criminal justice system" (Mental Health Commission of Canada, 2012, p. 24) as a priority, and recommending that the availability of different types of diversion programs be increased. 
As noted by the Mental Health Commission, mental health diversion programs are one solution that is aimed at addressing how offenders with mental illness are treated within the justice system. These programs differ from the mechanisms noted in Section 16 of the Canadian Criminal Code that are used to manage offenders with mental illness who have been found not criminally responsible or unfit to stand trial (Criminal Code, 1985, s. 16). In the case of diversion programs, clients must have the capacity to consent to participation, which would suggest they are less acutely mentally ill than individuals who are found not criminally responsible or unfit to stand trial. Diversion clients would also typically have committed minor crimes, as this is a criterion for diversion eligibility, whereas not criminally responsible or unfit to stand trial do not have these criteria. Although there is a large amount of heterogeneity among these available programs in terms of length, supervision, admission criteria, etc., almost 20 years ago Steadman, Morris, and Dennis (1995) identified six components that they suggested are vital to successful diversion programming:

1. Integrated services (co-ordination and co-operation between correctional and mental health services);

2. Regular meetings (regular meetings held between agency representatives to facilitate the coordination of cross-agency services, as well as meetings for service providers who directly interact with clients);

3. Boundary spanners (having a liaison to manage/facilitate the integration of services);

4. Strong leadership (a strong leader who has a strong grasp of all components of the program;

5. Early identification (identifying clients with mental health needs who may benefit from diversion programming as soon as possible upon detention because there is the chance they will be released before they can be screened); and 
6. Case management (culturally diverse case managers who have extensive criminal justice and mental health experience and who provide extensive assistance and monitoring to clients).

Despite differences in the particular components of available diversion programs, their common shared goal is to reduce or avoid jail time for mentally disordered accused, and to provide services to these individuals in order to reduce the likelihood of new criminal charges. This is achieved by developing plans to connect them with community services and supports that address their mental health and psychosocial needs.

\section{Diversion Effectiveness}

Consistent with its goals, mental health diversion overall has been shown to increase the time that offenders spend in the community compared to nondiverted offenders (Lange, Rehm, \& Popova, 2011; Steadman \& Naples, 2005). The implication of this is that diversion could be a cost-effective alternative to incarceration because it costs substantially less to maintain an offender in the community than in prison; the most recent estimates are $\$ 35,101$ vs. $\$ 117,788$ per year, respectively (Public Safety Canada, 2013). ${ }^{1}$ Given the wide diversity in mental health diversion programming, however, this apparent overall advantage requires further exploration. The literature discussed in this dissertation, therefore, will focus on postcharge mental health diversion programs, as these represent the closest match to the programs under examination. Both mental health court and non-mental health court programs will be considered, as one site examined in this dissertation used a mental health court model, making the literature on both types of programs relevant.

In an early study on a formal postbooking diversion program, Steadman, Cocozza, \& Veysey (1999) examined outcomes for 80 individuals who had been recommended for, and

\footnotetext{
${ }^{1}$ See also Hughes, Steadman, Case, Griffin, \& Leff (2012), who suggest that diversion programs are not uniformly cost-saving.
} 
agreed to participate in, mental health diversion. Overall, 35 individuals were successfully diverted, and 45 individuals were not diverted, subsequently continuing through traditional court processing. The participants underwent three interviews in total, the first within 24 hours of being identified for diversion, the second within one week of their release for the index offence, and the third, two months after diversion or booking. Overall, the majority of the sample was male, and Black. All individuals, both diverted and nondiverted, had lengthy criminal histories, with an average of 17 prior arrests. The majority of the sample, $95 \%$, had also been hospitalized in a psychiatric facility at some point in the past. However, when examining group differences, it was found that the diverted group was significantly more likely to be older and female, compared to the nondiverted group. The diverted group also displayed lower paranoid ideation scores, as measured by the Symptom Check-List-90-Revised (SCL-90-R) (Derogatis, 1983), and were less likely to have alcohol problems, as measured by the Michigan Alcoholism Screening Test (MAST) (Pokorny, Miller, \& Kaplan, 1972).

In regard to outcome measures, at the 2-month follow-up interview in the Steadman et al. (1999) study, all diverted participants had been released from jail. This was a significantly larger number than the 29 nondiverted participants who had been released. Only 18 nondiverted and 25 diverted participants were interviewed at follow-up, and the findings did not provide evidence that diversion was associated with better outcomes. There were no significant differences in rearrests between groups, which could potentially be related to the low number of nondiverted participants that had been released at the 2-month follow-up, but, surprisingly, the nondiverted group reported significantly larger improvements in quality of life and some domains of psychiatric symptomatology, such as anxiety and somatization. This finding could be explained by the diversion program not being effective; however, an alternate explanation for this finding 
could be that perhaps because mental health diversion programming was still in its earlier stages when this study was conducted, the process of linking diverted individuals to community supports was not yet adequate to evidence improvement in symptomatology.

More recently, other research provides some evidence for the effectiveness of diversion programming. In 2006, Moore and Hiday examined the outcomes of rearrests and rearrest severity and found that, consistent with expectations, mental health court participants had better outcomes on both measures. This study used a nondiverted comparison group of 183 individuals chosen for similarity in mental health status (although it is important to note that mental health diagnosis was not confirmed in the comparison group), demographic characteristics, criminal history, and current offence compared to the 82 individuals in the mental health court diversion group. Moore and Hiday found that, within the 12 months following entry into the mental health court or traditional criminal court period, the comparison group was rearrested more frequently than members in the diversion group who completed the full diversion program. Furthermore, the reoffences committed by the comparison group were more severe than the ones committed by the mental health court group. Comparisons between the diversion group that completed the full 6-month program (completers) and those who did not (noncompleters) indicated that completers had significantly fewer rearrests than the noncompleters, and the offending was less severe. Using multivariate analyses that allowed the researchers to control for demographic and criminological variables, mental health court completion was still a significant predictor of lower odds of rearrest, although not a significant predictor of rearrest severity.

Although these findings are positive, there are major limitations associated with the Moore and Hiday (2006) study. First, the comparison group was selected by the mental health court judge from offenders who had gone through traditional court processing in the time before 
the mental health court was running. As such, the presence of a mental health diagnosis was unconfirmed in this sample, leading one to question whether this was an appropriate comparison group. Second, although the authors note that the length of time to completion of the diversion program varied between individuals, this was not accounted for in the analyses. It would have been helpful to have information on the relationship between the length of diversion and recidivism. Not controlling for the length of supervision is problematic because it does not allow for a consistent follow-up period in which to assess reoffending. Although the authors operationalized recidivism as the number of rearrests within a 12-month period from the index offence, it is important to know how much time an individual spent under supervision during this time, as this would potentially have affected recidivism. By not factoring in the time spent in diversion, it is not clear whether the reduction in recidivism is related to the lasting effects of mental health court programming, or more stringent supervision.

A limitation to much of the earlier research on mental health diversion is the fact that it focused on single court sites. As Steadman, Redlich, Callahan, Robbins, \& Vesselinov (2011) note, this somewhat precludes the ability to draw conclusions that can be generalized to other sites/programs due to the wide variations across mental health court sites in terms of programming, community support available, etc. In order to address this limitation, Steadman et al. (2011) examined participant outcomes on measures of recidivism across four different court sites in the United States: San Francisco, Santa Clara, Minneapolis, and Indianapolis. This was a large, longitudinal study with an overall sample of 1,047 individuals: 447 newly enrolled mental health court participants, and 600 treatment as usual controls. These participants were followed for 18 months postenrollment. The treatment as usual group consisted of new jail detainees who had been identified by jail mental health staff as having possible mental health problems. The 
researchers attempted to match this group to the mental health court group on characteristics such as sex, index offences, race, age, and mental health diagnosis.

Steadman et al. (2011) found that the court sites had varying periods of supervision, and successful completion and termination rates, likely as a result of the variation in diversion programming from site to site. Overall, it was found that mental health court participants at all sites except Minneapolis were significantly less likely to be rearrested, even when examining annualized rearrest rates that take into account the time at risk for reoffending. Although the mental health court group experienced a small increase in jail days in the 18 months following enrollment, this increase was significantly smaller than the treatment as usual increase during the same period. The strongest predictors of annualized arrests and number of jail days were preprogram arrests and jail days (criminal history). A clinical factor that was an important predictor of both outcomes was receiving no mental health treatment in the 6 months prior to baseline. Having a diagnosis of schizophrenia or depression, as opposed to bipolar disorder, was significantly related to having more postenrollment jail days, as was having used illegal drugs in the 30 days prior to court enrollment.

One of the criticisms of outcome research in diversion programming is that the follow-up periods tend to be short and generally subsume the time period where the clients were under supervision. In order to address this issue, Burns, Hiday, and Ray (2013) examined the effect of mental health court participation on recidivism two years after program exit. This study utilized data from 99 clients of one mental health court in the United States. The recidivism outcome measures were a) whether there was any arrest, and b) the number of jail days within the two years following court exit. Overall, only $43.4 \%$ of participants graduated successfully from this program. The rest of the participants were terminated (43.4\%) or opted out of the program 
(13.1\%). Univariate analyses found a highly significant difference between postprogram arrests and jail days for graduates and nongraduates/opt-outs. While only $24.6 \%$ of the graduate group was rearrested in the two years following program exit, $90.7 \%$ and $76.9 \%$ of nongraduates and opt-outs were rearrested. The graduates also averaged only 2.8 jail days postprogram, compared to 202.3 and 113.6 jail days for nongraduates and opt-outs. The multivariate analyses found that, despite including predictors such as age, ethnicity, gender, and whether an individual had a cooccurring substance abuse disorder, adding mental health court graduation to the model subsumed all other predictors and became the only significant variable in the model when predicting rearrests. When predicting postprogram jail days, mental health court graduation was the strongest variable in the model, such that it predicted fewer jail days for graduates compared to nongraduates. Although prior jail days, duration of program enrollment, and Hispanic ethnicity were all significant predictors in the initial model that did not include graduation, once this variable was entered into the model, it reduced ethnicity and enrollment duration to nonsignificance. Prior jail days remained a significant predictor of more postprogram jail days, but graduation reduced the influence of this variable. An important additional finding in this study was that all of the participants who were homeless did not graduate the mental health court. Furthermore, all participants in this group recidivated during the 2-year follow-up and had a larger average number of postprogram jail days, compared to the mean of participants with housing. This finding underscores the importance of adequately linking participants to the community supports they may need in order to achieve successful diversion outcomes.

A final consideration in regard to the effectiveness of diversion programming is whether diversion programming is effective for violent offenders. This is a question of interest because although many programs will not admit these individuals regardless of the circumstances of the 
crime, some programs will allow individuals who have committed minor violent crimes.

Research by Naples and Steadman (2003) suggests that some individuals who have committed violent crimes may not necessarily pose an additional risk in terms of recidivism. In their study, which examined 12-month outcome data on violent offenders with mental illness and substance abuse, there were no significant differences between 113 violent offenders and 537 nonviolent offenders in self-reported arrests. Furthermore, it was found that the type of intake offence (violent or nonviolent) was unrelated to rearrests, hospitalizations, or emergency room visits after 12 months. Although the validity of this study could be called into question due to the fact that the rearrest data was self-report only, it suggests that more research on how specific types of charges relate to diversion outcomes is needed.

\section{Questions Remaining about Diversion Programming}

Despite the increasing popularity of diversion programs, there is debate in the literature as to whether these programs are effective, and even whether the logic behind them is sound. Two review articles have noted that, when examining the body of literature on diversion as a whole, the findings are not unequivocal. For example, in a recent literature review, Sirotich (2009) examined whether pre- and postbooking diversion programs had an effect on criminal justice outcomes. Overall, mixed evidence was found for the effectiveness of these types of programs. There did not seem to be evidence for a reduction in recidivism with diversion programming; however, there was evidence that, as expected and consistent with the goals of mental health diversion, diversion programs were associated with reduced amounts of jail time for the index offences. Other limitations noted by Sirotich included sample size, self-selected treatment groups, and a failure on the part of some included studies to control for relevant factors such as criminal history; these findings underscore the necessity of controlled research being 
conducted on diversion programming.

More recently, in their systematic review of postbooking and postincarceration diversion programs, Lange et al. (2011) determined the opposite - that there was moderate to high degrees of evidence that post-booking diversion schemes reduce recidivism. In the Lange et al. review, for all types of diversion models it was also noted that there was moderate evidence for reducing the number of days incarcerated. The evidence for diversion affecting service utilization and mental health status was less robust and depended on the diversion model examined. For example, there was evidence for moderate effectiveness for mental health court models improving mental health status, compared to limited effectiveness seen in jail-based models. The discrepancies seen between the findings of Sirotich's review and the Lange et al. review could possibly be due to the fact that many of the studies that found an effect for diversion in the Lange et al. review were not included in the Stirotich review, as it had an earlier publication date than the Lange review.

Predictors of outcome from the diversion literature. Several studies (e.g., Burns, Hiday, \& Ray, 2013; Hiday, Ray, \& Wales, 2014; Hiday, Wales, \& Ray, 2013; Moore \& Hiday, 2006; Steadman et al., 2011) have noted that completing the "full dose" of diversion programming (i.e., diversion completion/graduation) seems to be important to better outcomes in terms of recividism. Given this link between diversion completion and recidivism, an additional and less examined question is: Are there characteristics specifically associated with diversion completion (Case, Steadman, Dupuis, \& Morris, 2009)? This is an area within the diversion literature that as recently as 2010 has been noted as being scant: "The ability to answer the question of how to predict successful diversion is limited" (Ryan, Brown, \& WatanabeGalloway, 2010, p.474). Despite this, some research suggests characteristics that may be 
important to successful diversion. It is important to note first that there is not a standard definition of successful diversion. For example, some studies consider a reduction in rearrests following diversion from jail to be success, others consider the completion of diversion programming to be success, and some will use both indicators. The research presented below is representative of this issue, as both Case et al. (2009) and Barber-Rioja, Dewey, Kopelovich, and Kucharski (2012) use different measures of successful diversion outcomes.

Case et al. (2009) analyzed the data of 546 diverted clients from 14 postbooking diversion sites (non-mental health court) in order to better understand the predictors of success once an individual has been accepted into diversion programming. Overall, the sample contained approximately equal numbers of males and females ( $N=267$ and $N=279$ respectively). Bipolar disorder (26.3\%) was the most common Axis 1 diagnosis, followed by schizophrenia (24\%) and depression (24.7\%). More than half of the participants reported a lifetime history of sexual abuse (56\%), and almost all (91.4\%) reported a lifetime history of physical abuse. The most common class of offence was a misdemeanor $(68.7 \%)$. Compared to the 12 months prior to enrollment in the program, approximately $75 \%$ experienced fewer arrests in the 12 months following enrollment into the program. The number of days spent in jail pre- and postenrollment was also reduced overall (51.6 days compared to 34.5 days respectively). Criminal history was found to be related to postenrollment arrests; compared to the group that did not have any postenrollment arrests, the group mean for individuals who experienced at least one postenrollment arrest was higher for both prior arrests and prior jail days. This was also the case for postenrollment jail days, with individuals who had any postenrollment jail days, as opposed to no postenrollment jail days, having more prior arrests and jail days on average.

Consistent with the findings from the Burns et al. (2013) study, stable and consistent 
housing was also found to be significantly important to a postenrollment reduction in arrests. A limitation to the Case et al. study was the fact that the details of the program were not factored into the analyses. It was not noted whether all individuals were still under program supervision at the 12-month mark, or whether some individuals had graduated/been terminated from the program. More specifically, is this study assessing program compliance (participant is still receiving support) or recidivism (participant has graduated)? The authors state that participants were included in analyses if they completed at least one 6-month or 12-month postenrollment interview. It would have been helpful, however, to have separated the analyses based on the timing of the interviews because it seems reasonable to think, for example, that obtaining 12 months of treatment would be more effective than obtaining only 6 months. Despite these limitations, the results obtained by Case et al. suggest criminological factors (e.g., criminal history), and, to some extent, psychosocial factors (in the form of housing in this case) play an important role in diversion success.

In other research, Morgan, Fisher, Duan, Mandracchia, and Murray (2009) note that an important, and under-recognized, issue with the logic behind diversion programming is the fact that some mentally ill offenders have co-occurring antisocial tendencies (Morgan et al., 2009). This would suggest that, in these cases, addressing only the mental health issues may not be enough to prevent subsequent criminal offending. To investigate this, Morgan et al. conducted a study that examined the prevalence of criminal thinking (attitudes, values, and cognitions associated with criminal behaviour) among incarcerated adult males $(N=265)$ and females $(N=149)$. In this study, the prevalence of mental health issues was assessed using the Millon Clinical Multiaxial Inventory-III (MCMI-III), a 175-item true-false inventory that measures 14 personality patterns and 10 clinical syndromes (Millon, 1994), institutional records (for male 
offenders only), and, for a small proportion of the samples, the Structured Clinical Interview for DSM-IV Axis 1 disorders, which is a semi-structured clinical interview (SCID-I; First, Spitzer, Gibbon, \& Williams, 1997). A large number of participants were dropped from analyses because their self-report responses were deemed invalid (as indicated by the MCMI-III validity subscales). However, the included and excluded participants were not materially different, with variation existing between the two groups only in the fact that the included participants had approximately one more year of education compared to excluded participants.

Out of the 283 participants (178 males and 105 females) ultimately included in the Morgan et al. (2009) analyses, 92\% of participants were diagnosed with a serious mental illness such as schizophrenia or major depression. There was an issue with this statistic due to the fact that it was not clear where the authors obtained it from (i.e., whether it represents scores on the MCMI-III, institutional records, etc.). Despite this, it was clearly stated that $91.8 \%$ of males and $80.8 \%$ of females had elevated scores on at least one Clinical Syndrome Scale as measured by the MCMI-III, indicating some symptoms of a DSM-I Axis I disorder. The incarcerated sample was found to be similar in the prevalence of mental health problems (as measured by the MCMIIII) to non-offender psychiatric populations. They were also similar in measures of criminal thinking to offender populations, as measured by The Psychological Inventory of Criminal Thinking Styles [an 80-item self-report measure designed to measure thinking patterns associated with criminal behaviour such as entitlement, power orientation, and mollification (Walters, 2006)] and The Criminal Sentiments Scale-Modified [a 41-item self-report instrument designed to measure attitudes and beliefs associated with criminal behaviour (Simourd, 1997; Wormith \& Andrews, 1984)]. Some examples of attitudes and beliefs measured with the Criminal Sentiments Scale-Modified include attitudes towards the law, the courts, and the police 
(e.g., "Pretty well all laws deserve our respect") and beliefs such as tolerance towards law violations (e.g., "A hungry man has the right to steal”) (Simourd \& Van De Ven, 1999, p. 92). Although this study was limited by the fact that it did not include any control groups, and also the fact that professionally-obtained mental health diagnoses were only available for a proportion of the male sample, Morgan et al. suggest that the results indicate that offenders with mental illness may also have criminological needs that will likely not be addressed with only mental health treatment.

Criminological, as well as clinical, predictors were of interest in Barber-Rioja, Dewey, Kopelovich, and Kucharski's 2012 study examining the effectiveness of the HCR-20 [a tool designed to assess the risk of future violence in adult offenders with a history of violence and/or a major mental disorder or personality disorder (Webster et al., 1997)] and the PCL-SV [a screening tool based on the PCL-R that is designed to screen for psychopathic traits (Hart, Cox, \& Hare, 1995)] in predicting reincarceration and diversion noncompliance. The total sample size was 131 clients, 71 of whom were administered a battery of assessments as part of a wider study; the remainder of the data was collected by scoring the PCL-SV and HCR-20 from 60 additional randomly-selected files. Participants and files were obtained from three mental health courts and three diversion programs in New York. The clients ranged in age from 18-59 years (Mean Age $=$ 37.32), and contained $90(68.7 \%)$ males and 41(31.3\%) females. The majority had a history of mental health treatment and a history of substance abuse (93.1\% and $92.4 \%$ respectively). The most common disorder was major depressive disorder (29.8\%), followed by bipolar disorder (26.0\%) and schizophrenia (19.15\%). Eighty-two percent had a prior criminal history and $75.6 \%$ were charged with a felony crime. The majority of clients $(52.7 \%)$ were charged with a substance-related crime. Only $27.5 \%$ of the total sample was charged with a violent crime. 
Barber-Rioja et al. (2012) found that the HCR-20 significantly predicted diversion noncompliance, even after the PCL-SV score was controlled for. This is perhaps not a surprising finding given the item content of the HCR-20 and how, at face value, it seems as though these variables would be very relevant to diversion success or compliance. This particular risk scale encompasses historical factors (e.g., a history of violence, relationship problems, employment instability, substance use, history of major mental illness, etc.), clinical factors (lack of insight, current active symptoms of a major mental illness, lack of response to treatment, etc.), and risk management factors (e.g., plans are not feasible, lack of support, exposure to destabilizers, etc.) (Webster et al.,1997). The HCR-20 and PCL-SV both predicted reincarceration, but neither scale was significant when the other was statistically controlled for. The Risk Management scale (which includes items such as personal support, exposure to destabilizers) of the HCR-20 was the most effective scale at predicting diversion noncompliance at the 6- and 12-month follow-up period, although both the Risk Management and Clinical scales were significant predictors at the 3-month mark. The authors suggest these results indicate that risk assessment tools such as the HCR-20 could be useful in helping to inform diversion program decision-making. The relevance of the HCR-20 Clinical Scale in predicting diversion noncompliance at the 3-month mark, also indicates the importance of timely and effective treatment.

It is interesting that, despite the fact that mental illness is assumed to have played a large role in a diversion client's offending, there is not strong evidence for the importance of clinical factors in the prediction of diversion completion or criminal justice outcomes such as recidivism. For example, Keator, Callahan, Steadman, and Vesselinov (2013) specifically examined treatment access in a sample of mental health court participants and a treatment as usual group. Drawing from the same courts analyzed in Steadman et al. (2011), 296 mental health court 
participants and 386 treatment as usual jail-detainees were recruited from three court sites for this study. All participants completed a baseline interview, and 70\% completed a 6-month follow-up interview.

It was found that the mental health court group accessed significantly more crisis and treatment services in the 12 months prior to their program enrollment compared to the treatment as usual group. This was still the case in the 12 months postenrollment, with the exception of the crisis services. Postenrollment, the mental health court group no longer accessed more crisis services than the treatment as usual group, suggesting this group was stabilized by the assistance with accessing treatment and supervision associated with their enrollment in the mental health court. Enrollment in mental health court also impacted how quickly participants obtained treatment services. The mental health court group accessed community treatment significantly more quickly, compared to the treatment as usual group (a median of 7 days, compared to 64 days respectively). Given that diversion attempts to reduce offending by linking participants with community treatment, it is perhaps a surprising finding that whether a client accessed treatment in months 1-6 of their enrollment in the mental health court was not related to their annualized arrests or jail days in months 7-18. This finding of nonsignificance held even when control variables such as treatment linkage prior to court enrollment were included in the analyses. Keator et al. suggest that these findings indicate a need to include variables that measure what happens during treatment (e.g., how actively an individual is involved in treatment) versus simply including treatment variables as count variables (e.g., how many treatment sessions did the client receive).

The most recent piece of research to examine this issue looked specifically at the predictors of mental health court graduation (Hiday, Ray, \& Wales, 2014). A main question of 
interest in this study was the relative importance of program factors (e.g., noncompliance), compared to factors that were more static (e.g., criminal history) in predicting mental health court graduation. This study used data from a large urban mental health court in the United States that had a relatively short period of supervision (i.e., typically 4-6 months). The data from 408 participants was analyzed, which represents all participants from the first 2 years of this particular court. It excluded participants who were terminated for administrative reasons, failure to attend their first court hearing, or participants who were sent to traditional court at their first hearing. Overall, $58.3 \%$ of the participants graduated from the mental health court. The remaining portion of the sample represented individuals who had been terminated from the court. The results from the univariate analyses found that individuals who were terminated from the court were more likely to have been charged with a drug offence and test positive for drug use at index arrest, and have a larger number of arrests in the 2 years prior to the index arrest. Noncompleters were also significantly more likely to have noncompliance meetings with their case managers, have at least one fail to appear, and to be arrested during their participation.

Two sets of multivariate analyses were conducted in the Hiday et al. (2014) study; the first included the entire sample, and the second set was conducted on a subset of the sample that had information on case manager meetings. For both samples, the model which only included the variables a participant brought into mental health court (e.g., age, gender, race, prior criminal history) found that, race, number of prior offences, and drug use at the index offence were significant predictors of graduation, such that White participants had higher odds of graduation, whereas the number of prior arrests and illegal drug use at the index offence lowered the odds of graduation. Once variables relating to a participant's behaviour during mental health court were included in the model, only race remained a significant predictor across samples, but any fail to 
appears, arrests, and a higher drug test ratio (number of positive drug tests compared to number of drug tests administered) negatively impacted completion, with a final Nagelkerke $R^{2}$ of 0.54 for the full sample and 0.62 for the subset sample.

Hiday et al. (2014) suggest that these findings indicate that a failure to change past negative behaviours (as captured in the noncompliance predictors) are critical to success in mental health court. A limitation with this study, however, is that, typically, the criteria for successful completion of mental health court is some level of compliance with the programming. As such, it seems that this is not the most informative variable to be focusing on, as one would assume that, by definition, noncompliance would be strongly predictive of termination. It could potentially be more useful to focus on predictors that could lead to noncompliance in order to identify targets for intervention, by which noncompliance could be reduced.

Relevant nondiversion literature on potential predictors. Although the literature on diversion programming is somewhat limited in terms of the information it can provide about predictors of diversion outcomes, there is some evidence for the importance of criminological factors, and some evidence that psychosocial factors, such as housing, and clinical factors, such as illegal substance use, can have an impact on diversion completion and recidivism. It is interesting to note, however, that the importance of these types of predictors is not unique to diversion outcome. They have also been noted as predictors of legal involvement and recidivism in nondiversion samples of offenders with mental illness.

In their 2007 paper, Osher and Steadman suggest that mentally ill individuals involved with the justice system have unique needs that require adaptations to evidence-based practices. In addition to criminal histories and legal issues, they note that there are multiple psychosocial needs specific to this population that are relevant to clinical outcomes and must be considered 
when planning interventions. These needs include the fact that many mentally disordered offenders have co-occurring substance abuse issues, difficulty finding and keeping stable employment and housing, and many have a history of trauma.

In empirical research that provides support to Osher and Steadman's position, Sheldon, Aubry, Arboleda-Florez, Wasylenki, and Goering (2006) analyzed data from three community mental health programs/agencies (i.e., Assertive Community Treatment and Intensive Case Management) in Ontario, Canada. They compared 415 clients (92 legally involved and 323 not legally involved) on a number of characteristics. Results indicated that significant predictors of legal involvement were male gender, non-white ethnicity, unstable housing, being on social assistance, reporting less social support, and scoring higher on measures assessing substance abuse. Although the overall amount of mental health symptomatology was high in both groups (as measured by the Brief Psychiatric Symptom Scale (Overall \& Gorham, 1988), it was not found to be significantly related to legal involvement.

The Sheldon et al. (2006) study provides evidence for the role that variables from multiple domains may play in criminal offending within mentally disordered populations. However, two major limitations with Sheldon et al.'s study must be noted. First, legal involvement was operationalized by whether an individual had (in the past nine months) been arrested, spent at least one night in jail, or been on probation or parole. As such, there is some question whether these predictors would hold if the outcome variable was serious criminal charges or violent offences. Specifically, this operationalization does not allow us to rule out the possibility that psychosocial predictors, such as unstable housing, are in fact related to spending a night in jail for a nuisance offence, such as public intoxication, but are not related to more serious offences, such as assault. Second, as noted by the study authors, two of the programs 
used in this study specifically targeted individuals with mental illness who were unstably housed or homeless. Because the sample size was too small to examine differences between sites, it is unclear whether these significant findings would generalize to other programs.

Noting that the relationship between housing and crime in mentally ill homeless individuals has been an under-examined topic, Fischer, Shinn, Shrout, and Tsemberis (2008) conducted a longitudinal study over 48 months of 207 mentally ill homeless participants. In terms of nonviolent crime, it was found that both sheltered (defined as an emergency shelter or drop-in center) and nonsheltered (defined as a public area such as a subway/bus, abandoned building, the street, etc.) homelessness predicted nonviolent crime. However, there was a significant interaction between lifetime amounts of homelessness and nonviolent crime. Specifically, the likelihood of nonviolent crime increased in sheltered participants as their cumulative lifetime homelessness increased. The authors interpret this finding to suggest that, as individuals experience longer periods of nonsheltered homelessness, they may make more use of both legal and illegal subsistence strategies. Surprisingly, only sheltered homelessness predicted violent crime, possibly due to the fact that sheltered environments may create situations that lead to violence, either through the living conditions themselves or because shelters increase contact among individuals who are already highly stressed. Higher psychiatric symptomatology scores did predict both nonviolent and violent crime. However, age and living situation at baseline (whether an individual was recruited from a psychiatric hospital or the street) moderated the relationship between high symptom severity and violent crime, such that these predictors became much more relevant at higher levels of symptomatology. The Fischer et al. (2008) study was limited in the sense that it utilized self -report methodology for collecting data (i.e., criminal activity), but it further underscores the importance of considering the contextual factors that may 
be related to criminal activity.

By conducting a large meta-analysis on 64 unique samples from studies spanning 19591995, Bonta, Law, and Hanson (1998) were able to examine 74 predictors of general and violent recidivism in mentally disordered offenders. Overall, it was found that clinical predictors such as diagnosis and treatment had the smallest effect sizes in predicting both types of offending. In this meta-analysis, the effect size used was $Z r$, which is a Pearson's $r$ normalized and weighted based on the inverse of the variance, in order to account for differences in sample size. Consistent with the general offending literature, criminal history variables, such as prior violent offending or a record of juvenile offending, were significant predictors of recidivism, with effect sizes $(\mathrm{Zr})$ ranging from .18 to .30 for general recidivism and .13 to .26 for violent recidivism.

Some psychosocial predictors (referred to as deviant lifestyle-history variables) were shown to be significantly, although moderately, related to recidivism. For example, poor living relationships, family dysfunction, and substance abuse were all significantly related to general recidivism, with effect sizes of $.12, .10$, and .11 . The psychosocial predictors of violent recidivism were slightly different, with employment problems being the best predictor $(Z r=.22)$, and family problems and substance abuse also significantly predicting the outcome $(\mathrm{Zr}=.19$ and .08 respectively).

Bonta, Law, and Hanson (1998) suggest that, based on the fact that the criminal history variables were the best predictors of recidivism, general offending literature can inform risk assessment in mentally disordered offenders as well. This is consistent with much of the research presented in the current proposal on the importance of criminological factors to diversion success. The fact that some psychosocial predictors were found to be significantly related to recidivism in this study suggests that these factors should be considered as well, particularly 
because, unlike criminal history variables, these factors are more dynamic - that is, they could be targeted in diversion programming.

In 2014, Bonta, Blais, and Wilson conducted another large meta-analysis of 126 studies that again focused on general and violent recidivism in mentally disordered offenders. This updated meta-analysis was concerned with examining whether risk factors from a social learning perspective of crime (e.g., criminological and psychosocial factors) or from a more clinical model of crime (e.g., clinical variables) were the strongest predictors of recidivism in offenders with mental illness. As in the Bonta et al. 1998 study, both types of recidivism were best predicted by criminological and psychosocial factors. The strongest predictors of general recidivism were the domains of Substance Abuse (which contained the factors of past/current alcohol or drug abuse, and general substance abuse) $(d=.51)$, Procriminal Attitudes and Cognitions $(d=.37)$, and Antisocial Personality Patterns (which contained numerous factors such as early antisocial behaviour, escape history, and financial problems, etc. $)(d=.41)$. When considering violent recidivism, in addition to Procriminal Attitudes/Cognitions $(d=.51)$ and Antisocial Personality Patterns $(d=.57)$ being strong predictors, Criminal History $(d=.50)$ was also found to be important. Clinical variables were found to be nonsignificant in the prediction of both general and violent recidivism, with the exception of antisocial personality/psychopathy (this variable was also considered a factor within the Antisocial Personality Patterns factor noted above) ( $d=.54$ and .66 , respectively), personality disorders ( $d=.44$ and .41 , respectively), and, to a lesser extent, intelligence ( $d=.26$, general recidivism only).

Although there have been a number of psychosocial variables identified in the literature that could be impacting the relationship between mental illness and crime, Sirotich (2008) noted that many of the relationships are complex, and more research is necessary. According to 
Sirotich, although some predictors such as age, gender, and socioeconomic status have been quite extensively examined within the general offending literature, in some cases these predictors have been found to be less robust in forensic samples. He also notes that some variables are only just beginning to be explored, such as the role of social support and the role of intoxication (as opposed to more chronic substance abuse). Taken together, these findings and those presented above point towards the importance of considering psychosocial variables in research on mentally disordered offenders because, to date, the role that these variables play in offending is not clear.

\section{The Present Studies}

Given that there is debate in the literature about diversion effectiveness, the admission criteria that are appropriate for diversion programs, and the factors that are relevant to diversion success, the current research aims to address this gap (particularly in a Canadian context) by examining a number of research questions that will allow us to have a better understanding of who is referred and accepted into diversion programs, as well as the factors associated with diversion success. In addition, it is intended that this information be used to create an empirically-based screening tool that could be used by court workers in order to estimate the likelihood of a client's successful completion of a diversion program. The specific research questions can be found below within the rationale of each proposed study.

\section{Method}

\section{General Program Information}

The mental health diversion programs examined in the current research are administered by the Mental Health Court Support Consortium, a network of organizations that provide mental health court support to the five courthouses in the Greater Toronto Area. The mandate of this 
consortium is to reduce or prevent criminal justice involvement for individuals over 16 with serious mental illness and who have been charged with a criminal offence. One of the mechanisms by which this is accomplished is through pretrial (postcharge) diversion, in which an individualized community treatment plan is developed for the client. The aim is to prevent the client's further involvement with the criminal justice system by connecting him or her with clinical and social services and supports that address mental illness and psychosocial issues. Anyone can refer potential clients to these programs, but acceptance into the program is at the discretion of staff based on fit to program criteria, open spaces, and an individual's cooperativeness/willingness to participate.

\section{Mental Health Court Support Consortium Diversion Procedure}

Although mental health diversion could occur at a number of points, in the case of the Mental Health Court Support Consortium, diversion is pretrial and, unlike many of the diversion programs in the United States, it does not require the client to enter a guilty plea. If the Crown believes mental illness is the underlying cause of the criminal conduct, the accused may be eligible for mental health diversion, and, if successful (e.g., adheres to treatment recommendations), the charges may be stayed, withdrawn, or the Crown may order a peace bond (i.e., a court order requiring an individual to keep the peace and be of good behaviour), instead of pursuing a conviction. According to The Mental Health Court Support Consortium (2005)

criteria for mental health diversion (p. 13), in order to be eligible for diversion, an individual must:

1) Be suffering from serious mental health impairment (e.g., schizophrenia, bipolar disorder, etc.).

2) Be charged with a relatively minor offence; the Crown memorandum on diversion 
(Ontario Ministry of the Attorney General, 2005) classifies offences into one of three types: Class I, Class II, and Class III. Class I offences are considered presumptively divertable offences in that they are typically minor, nonviolent offences (e.g., theft under $\$ 5,000.00$, mischief under $\$ 5,000.00$, fraud under $\$ 5,000.00$, etc.). Class II offences are offences that are eligible based on Crown discretion (offences that closely resemble Class 1 offences are more likely to be diverted, e.g., property crimes under $\$ 5,000.00$, minor assaults). Class III offences are noted as not divertable in the Crown memorandum, but anecdotal information suggests that they may be considered on a case-by-case basis depending on the circumstances of the offence. An example of a Class III offence that may be diverted would be a sexual assault, for example if the offender grabbed someone but was experiencing psychosis at the time.

3) The potential client and mental health court support worker must agree to work together on mental health diversion, understanding that diversion is voluntary and that the client can withdraw from the program at any time in order to proceed through the criminal justice system.

4) Not have entered a guilty plea.

5) Not be in custody.

Although there is some variability from court site to court site, if the client wants to pursue mental health diversion, and if the Crown has agreed that diversion is an option, the court support worker will conduct an assessment, link client to needed services, and obtain documentation from the client's physicians about the client's suitability for diversion and treatment compliance. Once the client has been linked to services and is following treatment recommendations, the court support worker will provide the Crown with that information and the 
Crown will decide on a disposition (usually, stay the charges).

\section{Data Collection}

The data utilized for this dissertation were obtained from a common database maintained by the members of the Mental Health Court Support Consortium. Obtaining permission to access this database and preparing the data for use was a lengthy 2-year process. Because there are a number of individual agencies that operate the court support programs, it was necessary to obtain permission from each member agency in order to access their data. Then, after the datasets were merged, repeat admissions were identified, and a number of variables were recoded, a large amount of missing data was identified. In order to address this gap, the partner agencies were asked to use their case files to fill in as much missing data as possible, a process that took months. Additional cleaning and recoding of the dataset was the conducted, resulting in the dataset used for the current series of studies. In total, data from five different court sites in the Greater Toronto Area - Scarborough, Etobicoke, College Park, North York, and Old City Hall/102 - were used. The data spans one year of service at each location, for male and female clients who have applied for mental health diversion.

\section{Variables}

The main dependent variable of interest was diversion completion (coded dichotomously as successful or unsuccessful). For the present study, diversion success is defined as an individual having his or her charges stayed or withdrawn, or being given a peace bond, none of which results in a criminal record. Unsuccessful diversion refers to an individual either not being approved for diversion, dropping out of the program, or being non-compliant with the program. This outcome comprises both procedural (i.e., not being approved for diversion) and individual (e.g., dropping out of the program) reasons for unsuccessful completion. Seventy-seven 
individuals comprised the not approved/not eligible group, and 126 comprised the dropout/noncompliant group, for a total number of 225 unsuccessful divertees. In the diversion programs under examination in the present study, diversion was not a linear process. Specifically, while waiting for crown approval, an individual could have started his or her diversion program and/or begun to receive services prior to an approval/no approval being made by the Crown. Given this, it was decided that it would be appropriate to combine the not approved group and the dropout/noncompliant groups into the unsuccessful outcome. An additional reason for this is pragmatic: given the number of predictors that will be examined, an $N$ of 126 would likely not be large enough to have sufficient power for the analyses, particularly given the missing criminal history data. Although in some cases individuals in the not approved category would be inappropriate for diversion, in order to have been referred to the program initially, there would have to have been some concern on the part of court workers, defense attorneys, etcetera, in regard to mental health/psychosocial issues, and also a belief that the diversion program may accord some benefit to their clients. As such, it was believed that any meaningful differences between these two groups would likely be small, further suggesting that it was appropriate to combine them for the current set of studies, particularly given the non-linear nature of the programs under examination.

The common database contains approximately 500 variables, many of which were not relevant to the present set of studies. Therefore, the present studies utilized a subset of these variables that were selected based on their potential to contribute to the current analyses, as well as past research on mental health diversion. Variables related to the administrative aspects of the program (e.g., the name of a client's specific court worker) were excluded from analyses. For variables that had multiple categories (e.g., primary diagnosis, living situation, housing, primary 
income, etc.), the categories were recoded and collapsed together where possible. A table detailing how the categorical variables were recoded is presented in the Appendix. The list of variables used in the present studies, their descriptions, categories, and operational definitions is presented in Table 1. 


\section{Study 1}

\section{Rationale}

As noted above, Study 1 was concerned with better understanding the overall diversion sample, as well as a preliminary examination of the univariate associations between each of the variables and diversion outcome. The results of this study address the following research questions:

1. What are the characteristics of the diversion clients?

2. What are the factors relating to each type of diversion outcome (e.g., failure due to not being approved for diversion, failure due to dropping out/noncompliance, and success)?

In addition to contributing to the literature on diversion in its own right, the results obtained from Study 1 were also used to subsequently investigate mental health diversion in more depth in Study 2 and Study 3.

\section{Method and Analyses}

As a first step, the data for Study 1 were thoroughly cleaned and recoded as necessary. The nonviolent and violent index offences were scored using the Cormier-Lang system. This scheme allows the quantifying of offences into scores based on the severity of the offence according to the Canadian Criminal Code (Quinsey, Harris, Rice, \& Cormier, 2006). Lower scores are associated with less severe offences. For example, an offence of "theft under $\$ 5,000.00$ " would be given a Cormier-Lang nonviolent severity score of 1 , whereas a homicide, the most severe violent offence, would be given a Cormier-Lang violent severity score of 28 . The Cormier-Lang is typically used to code the severity of an individual's criminal history. However, in the current set of studies, the Cormier-Lang only reflects the severity scores of the 
index offences, as there were no data available on the nature of historical criminal offences. Because the data spans a number of sites, and numerous individuals were involved with entering information into the database, initially there was a large amount of missing data. In order to address this issue, the participating agencies filled in missing data to the best of their ability using their files and case notes, resulting in a dataset that was as complete as possible. The original version of this dataset also contained data from individuals who may have had more than one admission into the court support programs. As there were not enough of these individuals to utilize these data as a separate group for analyses, and in order to maintain consistency within the analyses and avoid giving more weight to this group, the data from these 23 individuals were removed, leaving 719 cases. Finally, upon inspection of the dataset, it was found that one client had been waitlisted. This would have introduced a bias into the analyses because that client would not have accessed services as quickly as the other court support clients; therefore, this case was deleted, leaving a final sample of 718 diversion cases.

After ensuring the dataset was as complete as possible, the individual variables were then examined for missing data, the normality of the variables of interest, and the frequencies of the distribution of individuals within the categories of each variable. It was found that there was significant missing data in regard to critical variables that measured an individual's criminal history; the prior criminal history variable only had 354 cases. The results from a Little's MCAR test indicated that these data were not missing at random, $x^{2}=91.27, d f=42, p<.001$. Univariate analyses were then run between the predictor variables and a dichotomous dependent variable of criminal history known and criminal history unknown. These results can be found in Table 2. It was known that two court support program sites did not reliably access the available criminal history data as a result of time constraints on the part of the court workers. Consistent with this, 
the 102/Old City Hall and College Park sites had significantly higher than expected frequencies in the unknown criminal history group.

The unknown criminal history group had a significantly lower proportion of married individuals, and a significantly lower proportion of individuals with a primary or secondary mood/anxiety disorder. Housing type was also found to be important, with a significantly higher proportion of individuals with an unknown criminal history living alone or being homeless. This pattern of results is likely due to the different client demographics between the downtown and suburban courts, with a higher proportion of homeless individuals being seen at the downtown courts. Despite the fact that the criminal history variable was not missing at random, it was determined that, due to the importance of criminal history to the present study, and due to the fact that even with the missing data there was still a large usable sample, this variable was retained in the analyses.

The categorical variables were then recoded in order to reduce the number of categories and create categories with larger numbers of cases. Any category listed as "other" within the original dataset was recoded as unknown in the current dataset, as it was not possible to determine what alternatives the "other" category could be representing. As noted above, a chart detailing both the original variable categories and the recoded variable categories can be found in the Appendix. Three continuous variables had outliers that needed to be addressed: the CormierLang nonviolent and violent severity scores, and the total number of index offences. These variables were Winsorized in order to keep the relative order of the scores but still reduce the influence of extreme scores. After cleaning and recoding, descriptive statistics were obtained for the whole sample using means and frequencies. The diversion outcomes of interest (i.e., successful and unsuccessful diversion) were then examined using the appropriate statistics (e.g., 
chi-square and t-tests) in order to identify the univariate associations with each outcome. Despite the large number of planned comparisons, a statistical correction for the univariate analyses was not used because the analyses are exploratory.

\section{Results}

\section{Univariate Results on Overall Sample}

The first set of analyses focused on the association between the variables of interest and a) the overall sample of 718 diversion clients, b) the successful diversion clients, and, c) the unsuccessful diversion clients. The full set of descriptive and univariate analyses for these groups are presented in Table 3. Overall, $67.3 \%$ of the sample successfully completed their diversions, with $31.3 \%$ having an unsuccessful outcome. The diversion clients ranged in age from 18-80, with a mean age of 39 . The majority of these clients were single $(66.4 \%)$, male $(66.7 \%)$, and on some type of assisted income at both program entry and exit (80.2\% and 80.1\%, respectively). Although a portion of the clients were homeless at both program entry and exit (16\% and $12.1 \%$, respectively), the majority of clients lived in either market rental or subsidized housing.

The most common primary diagnoses were psychotic disorders (41.2\%) and mood/anxiety disorders (42.1\%). Overall, $27.9 \%$ of the sample had either a diagnosed or selfreported substance abuse issue. Although a large majority of clients (83.3\%) had at least one clinical presenting issue, only $37.8 \%$ had at least one clinical need to be addressed by the court support program. In regard to psychosocial needs and presenting issues, $53.6 \%$ had at least one psychosocial presenting issue, and $45.5 \%$ had at least one psychosocial need.

Only 354 cases had information on prior criminal history. Of these cases, $18.8 \%$ had a sentencing or offence event prior to their index offence. Overall, the sample had a mean of 2.48 $(S D=2.01)$ index offences, although this number varied widely (Winsorized Range $=1-14)$. In 
terms of the severity of offences as classified by the Crown memorandum on diversion, 429 individuals had a least one Class I charge, and 423 individuals had at least one Class II charge. Although less common, Class III charges were still represented in this sample, with a total of 132 individuals having at least one Class III index offence. The mean Cormier Lang severity score for nonviolent index offences was $2.51(S D=2.76)$ and $1.42(S D=2.05)$ for violent offences. The majority of the sample $(65.6 \%)$ was awaiting trial at their time of referral to the program and, overall, spent an average of $6.24(S D=4.75)$ months in the program.

\section{Univariate Relationships Between all Variables and Diversion Outcome}

After describing the diversion sample, univariate analyses were conducted on each variable and its relationship to diversion outcome. It was found that individuals who successfully completed diversion were significantly older than individuals who were unsuccessful or not approved for diversion, $M=40.17$ and $M=37.37$ respectively. Housing type at both program entry and exit was the only psychosocial variable associated with diversion outcome. It was found that, at program entry, there was a significantly larger proportion than expected of homeless individuals in the unsuccessful diversion category. At program exit, there were a significantly larger proportion of individuals in the unsuccessful diversion category who were either homeless or residing in an institutional setting. In addition, individuals who were residing in subsidized housing were represented at lower numbers than expected within the unsuccessful diversion outcome.

A number of criminological variables were shown to be significantly related to diversion outcome. There were no significant differences in diversion outcome based on the CormierLang violent offence severity scores. However, the successful divertee group had a significantly lower Cormier-Lang nonviolent offence severity score compared to the unsuccessful diversion 
group, $M=2.33$ vs. $M=2.95$ respectively. The successful divertee group also had a significantly lower mean number of index offences compared to the unsuccessful group, $M=2.36$ vs. $M=$ 2.78. Having a prior criminal history and having legal needs were shown to be associated with unsuccessful diversion, with a larger proportion than expected of unsuccessful divertees having both a prior criminal history and identified legal needs.

A surprising finding was that substance use issues were not related to diversion outcome which is in contrast to research that has found a link between substance abuse and recidivism, as well as legal system involvement more generally (e.g., Sheldon et al., 2006; Steadman et al., 2011). The only clinical variable related to outcome was total number of clinical needs an individual had. It was found that the successful divertee group had a lower mean number of clinical needs compared to the unsuccessful divertee group, $M=.49(S D=.73)$ and $M=.72$ (SD $=.90)$ respectively.

\section{Univariate Relationships Between All Variables and Criminal History}

In addition to examining diversion outcome, analyses were conducted on the subset of the sample that had information on criminal history $(N=354)$. These results can be found in Table 4 . It was found that the group with criminal histories had fewer women than expected, fewer individuals who were employed, and fewer individuals living with relatives at program entry. A prior criminal history was also associated with substance abuse issues and a higher proportion of individuals who were homeless at program exit than expected. Although the group with criminal histories had a significantly higher mean on the Cormier-Lang nonviolent severity scale compared to the group with no criminal history, $M=2.88(S D=2.73)$ vs. $2.09(S D=2.50)$, the opposite was the case for the Cormier-Lang violent severity scale. Surprisingly, the mean Cormier-Lang violent severity score for the group with criminal histories was lower than the 
mean score for the group with no criminal history, $M=1.17(S D=1.99)$ vs. $1.77(S D=2.10)$. Despite the significance of the statistical tests, these findings likely do not represent a practical difference, as both sets of means differed by less than one unit.

\section{Univariate Relationships Between All Variables and Reason for Unsuccessful Diversion}

In order to address Research Question 2, univariate analyses were conducted in order to more closely examine the relationship between each variable and the reason for unsuccessful diversion: specifically, being not approved for diversion vs. dropping out of diversion or being noncompliant with programming. The results are presented in Table 5. There was a significant relationship between unsuccessful diversion and gender. For males, there were a larger proportion of individuals within the not approved category, whereas for females, there was a larger proportion falling into the dropout/noncompliant category. The relationship between housing type and outcome was also significant. When looking at the outcome for homeless individuals, a greater proportion of individuals with no housing fell within the dropout/noncompliant category as opposed to the not approved category. This was the opposite for individuals living in subsidized housing or institutions; in these cases, a larger proportion fell into the not approved category. Another interesting finding was a significant relationship between primary diagnosis and outcome. It was found that individuals with a psychotic disorder were more highly represented in the dropout/noncompliant category, whereas individuals with a mood/anxiety disorder were more highly represented in the not approved category. 


\section{Study 2}

\section{Rationale}

The purpose of Study 1 was to understand the characteristics associated with the total sample of individuals who applied for diversion, as well as with diversion outcome. It was shown that individuals who were successfully diverted had significantly fewer clinical, criminological, and psychosocial issues, compared to those individuals who were not successfully diverted. The purpose of Study 2 was to extend on this information by using multivariate statistics to examine the predictors of diversion success through the evaluation of the following hypothesis:

Hypothesis 2-1: Variables from multiple categories (i.e., clinical, criminological, and psychosocial) will be identified as significant predictors of diversion success in the forced-entry regression model. Consistent with previous research, it was anticipated that criminological variables would be strongly negatively related to diversion success. It was also expected that homelessness, and substance abuse would be negatively related to diversion success.

\section{Method and Analyses}

In order to evaluate the contribution of all potential predictor variables equally within blocks, a hierarchical forced-entry regression analysis was calculated. The predictors were entered in the following order:

Block 1: Court Site, Criminal History (known prior criminal offences or sentencing events), Age, Gender.

Block 2: Sum Psychosocial Needs, Sum Psychosocial Presenting Issues, Marital Status, Baseline Living Situation, Baseline Housing, Baseline Employment, Baseline Primary Income. 
Block 3: Sum Clinical Needs, Sum Clinical Presenting Issues, Primary Diagnosis Mood/Anxiety, Primary Diagnosis Psychotic, Any Substance Use Issues.

Block 4: Total Index Offences, Sum Cormier Lang Nonviolent (Index Offences), Sum Cormier Lang Violent (Index Offences), Sum Legal Needs, Legal Status at Referral.

Block 5: Longest Length of Stay (in Months).

In the case of variables with baseline and exit values, only baseline values were used because exit information would not be available for all the clients who dropped out or were not approved for the program. For the need and presenting issues variables, all individual needs and presenting issues were summed across each broader domain (e.g., clinical needs, clinical presenting issues) to obtain a total score (the list of individual needs and highest possible scores within each domain are presented in Table 1). Although the individual variables could have been used as predictors, summing them across domains allowed a proxy measure of how high-need each client was, with higher scores representing higher levels of need. As noted in Study 1, missing data was a significant issue for some variables, particularly the criminal history variable. To address this, and to increase the overall $N$ to a number appropriate for the large number of predictors, variables with over 5\% missing data were recoded in order to include missing as a category in the analyses, increasing the $N$ to 599. For example, for the criminal history variable (whether an individual had known past offences or sentencing events), this meant that the possible categories for this variable were yes, no, and missing. The other variables that were recoded in this manner were legal status at referral, marital status, baseline primary income, and baseline employment.

\section{Results}

Consistent with Hypothesis 2-1, a number of predictors were found to be significantly 
related to diversion success in the forced-entry regression analysis. Overall, the full model was significantly better at predicting diversion success compared to the constant-only model, $x^{2}(36, N$ $=599)=150.36, p<.001$, with $78.8 \%$ of cases correctly classified, compared to $72 \%$ for the constant-only model, Nagelkerke $R^{2}=.32$. The Hosmer and Lemeshow test was significant, $p=$ .02 .

Significant criminological predictors of diversion success included criminal history and legal needs. Clinical predictors were less represented, with only clinical needs significantly predicting diversion success. One psychosocial predictor - marital status - was significant, as were the procedural predictors of longest length of stay and court site. The contrasts for prior criminal history indicated that individuals with a prior criminal history, as well as those with a missing criminal history, had significantly lower odds of success compared to individuals with no criminal history $(O R=.43$ and .40 , respectively). Having additional legal needs was also associated with lower odds of diversion success $(O R=.38)$. In terms of clinical predictors, having a larger number of clinical needs significantly decreased the odds of success $(O R=.74)$. The contrasts for marital status indicated that being married (vs. being single) was associated with higher odds of diversion success $(O R=2.23)$, although the confidence interval for this variable suggests this should be interpreted with caution $(95 \% \mathrm{CI}=1.04,4.77)$. Two contrasts for the court site variable were significant; compared to the 102/Old City Hall court, individuals at the Metro East court had lower odds of success $(O R=.30)$, whereas individuals at the College Park court had higher odds of success $(O R=1.98)$. Finally, longest length of stay was a significant predictor of diversion success, with every unit increase in length of stay associated with a 1.21 increased odds of diversion success. 


\section{Study 3}

\section{Rationale}

Study 2 found that there were a number of predictors associated with diversion outcome at the multivariate level. In order to more fully explore the relationship between the predictors and the outcome, in Study 3, block logistic regression was used, with stepwise entry within the blocks. The blocks were comprised of variables from each domain (i.e., demographic, psychosocial, clinical, criminological, and procedural) and allowed the examination of whether each individual category of predictors contributed to the explained variance. This technique could also potentially create a better-fitting model by including the predictors in a stepwise fashion within the blocks, based on their relationship with the outcome. If the results are similar to the forced-entry regression results, this would allow for more confidence in the identified model. The hypothesis to be evaluated remains the same as that from Study 2, specifically: Hypothesis 3-1: Significant predictor variables will be found within each category of variables (i.e., clinical, criminological, and psychosocial); however, a combination of variables from each category will account for the most variance in outcome (diversion success). Consistent with previous research, it was anticipated that criminological variables would be strongly negatively related to diversion success. It was also expected that homelessness and substance abuse would be negatively related to diversion success.

\section{Method and Analyses}

Hypothesis 1 was evaluated by multivariate logistic regression using block entry (stepwise entry of variables within each block). Predictors were chosen based on past literature, as well as their associations (as identified in Study 1) with diversion outcome. As in Study 2, in the case of variables with baseline and exit values, only baseline values were used because exit 
information would not be available for all the clients who dropped out or were not approved for the program. For the need and presenting issues variables, all individual needs and presenting issues were summed across each broader domain (e.g., clinical needs, clinical presenting issues) to obtain a total score (the list of individual needs and highest possible scores within each domain are presented in Table 1). Despite two contrasts for court site being significant in Study 2 , this variable was excluded from Study 3 analyses. There were a number of reasons for this. First, when initially discussing obtaining access to, and sharing, this dataset, it was decided in consultation with Dr. Sirotich that site differences would not be examined in the current set of studies, as Dr. Sirotich wanted to examine this in his own research. Second, the relationship between site, the predictors, and diversion outcome is likely complex, and will require an indepth examination in order to understand how site affects diversion outcome. There are certainly differences between sites at the program level (e.g., particular court workers, program philosophies, etc.), as well as at the client level in terms of demographic characteristics. This idea is borne out by the significant contrasts from Study 2, which suggest that there are differences between the mental health court program versus the non-mental health court diversion programs. The current sets of studies are a preliminary examination of the predictors of diversion success in the aggregated multi-site sample. Because any of the clients could have theoretically been sent to any of the courts, there is justification for not controlling for site, as ultimately, the current set of studies is concerned with identifying the predictors that are significantly associated with diversion outcome, irrespective of site differences the clients may encounter. As such, the court site variable was dropped from the following analyses in order to find a model that best predicts diversion success across all sites.

For each model, the variables were entered in the following order: 
Block 1: Criminal History (known prior criminal offences or sentencing events), Age, Gender. Block 2: Sum Psychosocial Needs, Sum Psychosocial Presenting Issues, Marital Status, Baseline Living Situation, Baseline Housing, Baseline Employment, Baseline Primary Income.

Block 3: Sum Clinical Needs, Sum Clinical Presenting Issues, Primary Diagnosis Mood/Anxiety, Primary Diagnosis Psychotic, Any Substance Use Issues.

Block 4: Total Index Offences, Sum Cormier Lang Nonviolent (Index Offences), Sum Cormier Lang Violent (Index Offences), Sum Legal Needs, Legal Status at Referral.

Block 5: Longest Length of Stay (in Months).

Because the outcome is dichotomous, logistic regression was used to predict successful diversion. Once the multivariate regression analyses were complete, receiver operating characteristic (ROC) analyses were used in order to compare the utility of the models in relation to each other (Swets, 1988). The statistic used by ROC analysis is referred to as the "Area Under the Curve" (AUC) statistic. These analyses provide a specific probability of hits (a correct prediction of the outcome) and false alarms (an incorrect prediction of the outcome), allowing for the selection of the model with the highest predictive utility. The AUC statistic is particularly useful for evaluating predictive accuracy because it considers the entire ROC curve, rather than only one ROC point (Bennell, 2005). AUC's can range from 0 to 1 , with higher numbers representing higher predictive accuracy, and AUC's at the midpoint (.5) indicating predictive accuracy at chance level. The AUC's were subsequently compared using MedCalc for Windows Version 9.2.1.0. (MedCalc Software, 2008), which allows for the testing of AUC's from samples that are potentially correlated, as would be the case in the current study. 


\section{Results}

\section{Multivariate Analyses}

As identified in Study 1, missing data for the prior criminal history variable was a significant issue. To address this within the analyses, four different regression models were run, in order to be confident in finding the best solution to deal with the missing data. Although all models used the same order of entry for the variables, each model differed in how the missing criminal history data were addressed. The results from the final block for all models are presented in Tables 7, 8, 9, and 10.

The initial model, Model 1, included the criminal history variable, but utilized listwise deletion, one of the recommended approaches for dealing with missing data (Tabachnik \& Fidell, 2007). As a result of this, only clients with known criminal history information were retained in the analyses. This model classified $84.8 \%$ of cases correctly, and had a Nagelkerke $R^{2}$ of .29 , although it is important to note that the Hosmer and Lemeshow test was significant, suggesting there are still variables that were not identified, which would account for additional variance. There are, however, some issues with this method of handling missing data. The first is the fact that listwise deletion can dramatically reduce the overall $N$, which is the case here. The second is that if the data are not missing at random, this approach has the potential to distort the sample (Tabachnik \& Fidell, 2007).

In order to address these issues and increase the overall $N$, in Model 2, variables with over 5\% missing data were recoded in order to include missing as a category in the analyses, increasing the $N$ to 612 . For example, for the criminal history variable (whether an individual had known past offences or sentencing events), this meant that the possible categories for this variable were yes, no, and missing. The other variables that were recoded in this manner were 
legal status at referral, marital status, baseline primary income, and baseline employment.

Overall, the full Model 2 was significantly better at predicting diversion success compared to the constant-only model, $x^{2}(13, N=612)=117.89, p<.001$, with $79.4 \%$ of cases correctly classified, compared to $71.9 \%$ for the constant-only model, Nagelkerke $R^{2}=.25$. As with Model 1, which used listwise deletion, the Hosmer and Lemeshow test was significant for Model 2.

Including missing as a category increased the importance of criminological predictors to the model. In Model 2, significant criminological predictors of diversion success included criminal history, the Cormier-Lang nonviolent severity score, legal status at referral, and legal needs. Clinical predictors were less represented, with only clinical needs significantly predicting diversion success. Finally, the procedural predictor of longest length of stay remained significant. The contrasts for prior criminal history indicated that individuals with a prior criminal history, and those with a missing criminal history, had significantly lower odds of success compared to individuals with no criminal history ( $O R=.48$ and .52 , respectively). A larger Cormier-Lang nonviolent severity score significantly lowered an individual's odds of diversion success $(O R=.89)$. Legal status at referral was a significant predictor overall, but none of the contrasts were significant. However, looking at the odds ratios, it appears that individuals with a missing legal status had lower odds of successfully completing diversion compared to individuals awaiting bail, trial, or sentencing. In terms of clinical predictors, having a larger number of clinical needs significantly decreased the odds of success $(O R=.73)$. Finally, longest length of stay remained a significant predictor of diversion success, with every unit increase in length of stay associated with a 1.20 increased odds of diversion success.

As noted above, the criminal history variable had approximately 50\% missing data and these data were not missing at random. In order to be confident that the missing data were not 
affecting the obtained results, the regression analyses were re-run excluding this variable. Model 3 used listwise deletion and excluded criminal history, $N=424$. The full model was significantly better at predicting diversion success compared to the constant-only model, $x^{2}(7, N=424)=$ $61.30, p<.001$, with $81.1 \%$ of cases correctly classified, compared to $78.1 \%$ for the constantonly model, Nagelkerke $R^{2}=.21$. The Hosmer and Lemeshow test was significant.

Consistent with the previous models that included criminal history, a combination of clinical, psychosocial, criminological, and procedural variables were found to best predict diversion success. In this model, baseline housing was a significant predictor overall, and the contrasts for this variable indicated that, compared to individuals in a private house/market rent home, individuals who were homeless or institutionalized had significantly lower odds of diversion success $(O R=.41$ and .41 respectively $)$. Once again, clinical needs was a significant predictor, with each unit increase in this variable associated with .68 odds of success. The Cormier-Lang nonviolent severity score was the only significant criminological predictor, with each unit increase in the Cormier-Lang score associated with .89 lower odds of success. Finally, as in all previous models, longest length of stay was significant, with each unit increase in length of stay being associated with 1.23 higher odds of success.

For Model 4, criminal history was again excluded, and variables with more than 5\% missing data were recoded to include missing as a category (as in Model 2). The full model was significantly better than the constant-only model, $x^{2}(10, N=612)=103.56, p<.001$, with the full model correctly classifying $76.8 \%$ of cases compared to $71.9 \%$ for the constant-only model, Nagelkerke $R^{2}=.22$. Unlike the other three models, the Hosmer and Lemeshow test was nonsignificant in this model, although the overall percentage of correct classifications was the lowest of all the models. 


\section{ROC Analyses}

As noted in Table 11, the AUC's ranged from .70 to .76, indicating good levels of accuracy for all models (Swets, 1988). Model 2 had the highest AUC at .76; therefore, this model was used for the development of the screening tool in Study 3. When pairwise comparisons of all AUC's were conducted using MedCalc, Model 2 was found to be significantly more accurate than Model 1 (AUC Difference $=.05, p<.05,95 \%$ CI $[.01, .10]$ ). All other comparisons were nonsignificant. 


\section{Study 4}

\section{Rationale}

In Study 3 it was found that, consistent with Hypothesis 1, the model that best predicted diversion success contained a combination of predictors from psychosocial, clinical, criminological, and procedural categories. In Study 4, the model from Study 3 that had the highest AUC, and included the most comprehensive set of predictors, was used in order to create a checklist that could potentially be used in a court support setting to assess the probability of an individual successfully completing his or her diversion programming. Rather than being used as a risk assessment tool to exclude candidates who could be deemed "poor" candidates for diversion, the purpose of this checklist was to identify the supports and/or services that could help to facilitate a successful outcome.

\section{Method and Analyses}

Based on the results from Study 3, it was determined that the significant predictors from Model 2 (prior criminal history, legal needs, the Cormier-Lang nonviolent severity score, and clinical needs) would be used for the development of the screening tool. Although this model did not have the highest percentage of correct classifications, it did have the highest AUC and, unlike Model 3 and Model 4, included the criminal history variable. Criminal history has been shown to be empirically related to risk assessment and diversion compliance, and, as such, it was determined to be important to use a model that included this variable if possible. The intercorrelations among the four checklist predictors are presented in Table 12. Due to the missing criminal history data, there was not a large enough sample size to reserve a portion of cases that could be used in Study 4 as true development and validation samples (i.e., ones that were not used in Study 2 and 3). As such, in order to provide a construction sample and a sample 
that could be used to conduct an approximation of a split-half reliability procedure, the data were randomly split in half; with approximately $50 \%, N=361$, of the data used for the construction of the screening tool. Although a true scale validation cannot be conducted, by splitting the data in half, the scoring scheme can be evaluated by examining whether the risk categories are similarlydistributed in both halves of the sample. After splitting the dataset, each predictor was operationalized into a checklist item, and a scoring key for three different types of weighting was developed. The operationalized items and their scoring can be found in Table 13. The first scoring scheme was unweighted, the second was a ranked scoring scheme, and the third was a scoring scheme based on the beta weights. All coding schemes were scored to parallel the regression analyses from Study 2, such that higher scores were associated with diversion completion.

The two significant continuous predictors on the checklist were the Cormier-Lang nonviolent severity score for index offences, and the clinical needs variable. In order to operationalize the Cormier-Lang variable, it was transformed into a categorical variable based on the group means from the univariate associations with diversion success. As such, all CormierLang nonviolent severity scores under 3 were coded as " 0 ," and scores 3 and above were coded "1." This categorical coding was used for each checklist scoring scheme. The clinical needs variable was also recoded into a categorical variable, as additional univariate analyses showed that needing a physician or a psychiatrist were the only clinical needs that were significantly related to diversion success. The checklist clinical needs variable was therefore operationalized as needing either a physician or a psychiatrist (refer to Table 13 for scoring).

Once the variables were recoded based on each weighting scheme, they were summed in order to obtain a total checklist score for each client. ROC analyses were then used to obtain the 
AUC associated with each type of weighting.

\section{Results}

After obtaining a checklist sum for each client and each weighting scheme, descriptive statistics were run for the 361 cases that comprised the construction sample. The means (with standard deviations in parentheses) for the unweighted, ranked, and beta weighted checklist sums were 2.34 (1.08), 5.45 (2.84), and 9.02 (4.62), respectively. The different checklist weightings were then evaluated using ROC analyses. The results of this analysis can be found in Table 14. It was found that all of the weighting schemes predicted successful diversion at significantly better than chance levels. The AUC's ranged from .65 to .66, with the ranked and beta-weighted coding achieving the highest AUC values (.66). It was of interest to determine whether excluding the criminal history variable significantly impacted the overall predictive accuracy of the scale, as some of the court sites do not collect or have access to criminal history information. It was found that excluding the criminal history variable from the checklist impacted the predictive utility of the scale, dropping the AUC for each type of weighting scheme to .60.

Using the reliability sample $(N=357)$, descriptive analyses were run on the checklist sums for all three weighting schemes. The means (with standard deviations in parentheses) for the unweighted, ranked, and beta weighted checklist sums were 2.39 (.99), 5.53 (2.61), and 9.18 (4.26) respectively. ROC analyses were then run on all weighting schemes (Table 15). Once again, the AUC's predicted the outcome at better than chance levels but were ultimately lower than those obtained from the full logistic regression models in Study 3. In the reliability sample, the AUC's were .63 for the unweighted scoring scheme, and .64 for the ranked and beta-coded scoring schemes. As in the construction sample, once criminal history was excluded from the checklist scores, the AUC's decreased in all weighting schemes (AUC for all weightings = .61). 
Given that the AUC's for the ranked and beta-weighted coding were identical in both the construction and reliability sample (.66 and .64 respectively), all additional analyses were conducted using the ranked weighting, since it is the simpler coding scheme. In order to situate these AUC's within a practical context, chi-square statistics were computed for the rankedweighted checklist sums and diversion outcome (successful and unsuccessful) for both the construction and reliability samples (Tables 16 and 17). Due to small cell frequencies using the original distribution of scores, the checklist scores were then collapsed into three ranges that allowed for a larger number of individuals in each cell. The percentiles, sample sizes, and associated percentages of successful divertees for both the construction and reliability samples are presented in Tables 18 and 19. As seen in these tables, an increase in checklist score is associated with an increase in the proportion of successful divertees. There were significantly fewer successful divertees who scored within the low success range in both the construction and reliability samples. Within the construction sample, there were a significantly higher proportion of successful divertees scoring within the high success range. Although this relationship was in the same direction in the reliability sample, it did not reach significance. This could potentially be due to the fact that there were more missing cases in the validation sample. 


\section{Discussion}

Mentally ill offenders represent a significant issue for the legal and correctional system. This is especially the case when mental illness is thought to have played a role in an individual's criminal offending. In order to address this issue, mental health diversion programs have been created and have become quite popular across the United States and Canada. While research in the United States is creating a growing body of literature on this topic, much less research has been conducted in Canada. In order to address this gap, the current set of studies was conceived in order to better understand the characteristics of mental health diversion clients in Canada, as well as to examine the predictors of diversion success. Based on these predictors, a checklist was then developed in order to determine whether it could be of use to guide decision-making within court support program settings.

\section{Who are the Successful and Unsuccessful Divertees?}

The purpose of Study 1 was to better understand the characteristics of individuals who are successful and unsuccessful in mental health diversion, as well as to examine the univariate associates of diversion success. A number of variables were significantly related to diversion success. Overall, it was found that successful divertees tended to have fewer psychosocial, clinical, and criminological issues. Based on the univariate analyses, when compared to unsuccessful divertees, successful divertees tended to be significantly older, were less likely to be homeless at program exit, and had significantly fewer clinical needs. Unsuccessful divertees were more likely to have a prior criminal history and were more likely to be homeless or institutionalized at program exit. They were also more likely to have additional legal needs that were not related to their index offences, and they had a significantly higher number of index offences. These index offences were also significantly more severe, as rated by the Cormier- 
Lang nonviolent severity score.

These results suggest that individuals with higher levels of psychosocial, clinical, and criminological need are more likely to be unsuccessful in their diversion; however, because the diversion process is not linear, it is difficult to tease apart these findings to understand whether this is a result of systemic factors (i.e., the Crown not approving the diversion) or client behaviour (i.e., client dropping out or being noncompliant). Research Question 2 attempted to further examine these results by conducting univariate analyses in only the unsuccessful diversion group on the diversion outcomes of not approved and dropout/noncompliant. It was found that, overall, males were significantly more likely to fall within the category of not approved for diversion, whereas females were more likely to be dropouts/noncompliant, although it is important to note that gender was not significantly related to diversion outcome overall. This corresponds to research suggesting potential gender bias in diversion samples (e.g., Steadman et al. 1999), but because gender has not consistently been identified as a predictor of graduation or recidivism in all research, this is a finding that should be examined in future studies looking at admission criteria and selection processes. Although the current study does not provide enough evidence to suggest that a selection bias is occurring, other research has found evidence of this (e.g., Steadman, Redlich, Griffin, Petrila, \& Monahan, 2005), and it would be unfortunate if individuals were being excluded from diversion programming based on factors that are not empirically related to either program success or subsequent criminal justice outcomes.

Housing status was also found to be an important factor in unsuccessful diversion; individuals who did not have stable housing were more likely to fall within the dropout/noncompliant category. This finding corresponds to the literature on the importance of 
stable housing in individuals at risk of criminal offending (Case et al., 2009; Salem et al., 2014;

Sheldon et al., 2006) and suggests that it should be a priority to link clients to housing in order to facilitate their success in diversion programming. There were significant differences found between unsuccessful diversion outcomes in terms of primary diagnosis. Whereas individuals

with a diagnosis of psychotic disorder were more highly represented in the dropout/noncompliant category, there was a higher proportion of individuals than expected with mood/anxiety disorder in the not approved category. This finding suggests that perhaps individuals with mood/anxiety disorders are not seen by the Crown as having significant enough mental health issues to be eligible for diversion.

\section{What are the Predictors of Diversion Success?}

The purpose of Studies 2 and 3 was to examine the predictors of diversion success using multivariate analyses. Some of the significant relationships found in Study 1 were not borne out in the multivariate analyses. Despite this, Study 2 identified a number of variables that predicted diversion success at the multivariate level. In this forced-entry analysis, the variables that significantly predicted diversion outcome were criminal history, legal needs, marital status, clinical needs, longest length of stay, and court site. The fact that court site was significant in this analysis suggests that in future research it would be important to further examine the effect of site on the predictors of diversion success. The current dataset did not include information on specific court procedures that could be examined in order to better understand any identified differences across courts. However, it can be hypothesized that the effect that court site has on outcome is likely related to a number of factors, including demographic differences of the community in which the court is situated, and program factors such as individual court procedures. The fact that two regression contrasts that compared the mental health court model 
with a non-mental health court model were significant suggests that this is a question that should be more closely examined in future research. Despite the significance of this variable in the current study, court site was excluded from Study 3 and the screening tool (Study 4) because, ultimately, the current set of studies were concerned with examining predictors independent of court site, and with creating a standardized checklist that could be used in any of the court support programs. Also, there could be potential ethical issues with identifying differential success rates across the courts without having the mechanism to explain these differences. In order to further examine the variables at the multivariate level, in Study 3 block regression with stepwise entry within blocks was used. Finding similar results in these models to the forced-entry analysis allows for more confidence in the block/stepwise procedures. Due to the concern with missing data on the criminal history variable, four regression models were run in order to determine the most appropriate way to handle the missing data. Consistent with Hypothesis 3-1, it was a combination of variables from multiple domains that had the best predictive value. The AUC's from all models indicated good levels of accuracy in predicting diversion success. When comparing the AUC's from all models, it was found that only Model 1 and Model 2 differed significantly, with Model 2 having the best predictive value. Two variables were consistently, significantly related to diversion success in all models; specifically, clinical needs and the longest length of stay variable. The significance of the length within the program is likely due to the fact that, by definition, individuals who were successful in their diversions were in the program longer than individuals who dropped out, were noncompliant, or were not approved for diversion.

Regardless of the model, having more clinical needs was associated with reduced odds of diversion success. The fact that clinical needs were consistently related to diversion success, both 
in the univariate and multivariate analyses, but not a significant variable when examining only the unsuccessful diversion group suggests that this is an important area for the court workers to focus on. Ensuring that the diversion clients are appropriately linked to general practitioners, psychiatrists, etcetera, could potentially increase their likelihood of diversion success and is also consistent with the mandate and intention behind mental health diversion in addressing mental health and psychosocial needs that could be related to criminal behaviour. This is also an important finding because, in many cases, clinical factors have been identified as only weak predictors of outcomes, such as recidivism. A possible explanation for the significance of the clinical needs variable is that, rather than looking at a mental health diagnosis or symptomatology, this variable was a rough proxy for clinical support. Perhaps the relationship between clinical factors and diversion outcome/recidivism is more related to whether an individual has access to the treatment and support he or she needs in order to manage their mental illness, as opposed to the specific diagnosis he or she has. Additional univariate analyses examining the individual clinical needs, and successful and unsuccessful diversion outcomes, indicated that needing a physician or psychiatrist was significantly and negatively related to diversion outcome, such that there were a higher proportion of individuals needing either of these linkages in the unsuccessful diversion group. This supports the idea that ensuring the appropriate supports are in place could help to facilitate diversion success.

The Cormier-Lang nonviolent severity score for the index offences was a significant predictor in three out of the four Study 3 regression models. In all cases, as the severity of index offences increased, as measured by the Cormier-Lang, the odds of successful completion of diversion decreased. This finding is consistent with the suggestions from other researchers (e.g., Bonta et al., 2014; Bonta et al., 1998; Morgan et al., 2009), who note that, while mentally ill 
offenders have unique mental health needs, as seen in the current set of studies by the significance of the clinical needs variable, they are also similar to criminal offenders in that criminological characteristics are also important to their program and criminal justice outcomes.

It would have been helpful to be able to have been able to include a variable that measured whether the various needs were met within the diversion programming. This would have enabled the examination of whether or not individuals who had more needs addressed within the program had increased odds of diversion success, and whether this change in service status was more important than the actual number of needs with which a client came into the program. Within the literature on diversion, there is still a significant lack of understanding regarding the mechanism by which diversion seems to affect recidivism. There is research showing it reduces postprogram jail days and arrests, but given the variation in programming, it is difficult to say what the "active" components of a diversion or mental health court program are. By better recording and examining dynamic variables - specifically, what changes clinically, criminologically, and psychosocially for a client during diversion - a fuller understanding of how, and for whom, diversion works could be achieved.

It was surprising that variables expected to be important to diversion outcome, such as criminal history, housing status, and age, which were significant in the univariate analyses, were not significant in all models at the multivariate level, particularly because these variables have been shown to be linked to criminal offending in other research (Bonta et al., 2014; Case et al. 2009; Salem et al., 2014). When referring to Tables 7-10 from Study 3, it is observed that housing status becomes significant when criminal history is not included in the regression model. While beyond the scope of the current set of studies, it would be interesting to examine whether there are moderating variables that could affect the relationship between these variables and 
diversion success.

\section{Utility of Screening Tool}

Despite the fact that there were a number of predictors identified in Study 3 as important to diversion success, the checklist created in Study 4 using these variables did not predict diversion success as well as the initial regression model. This is likely due to the fact that not all the significant variables identified in the model were included in the checklist, and that the Cormier-Lang variable was converted to a categorical variable for the purposes of the checklist. In both the construction and reliability samples, the highest AUC's were found for the ranked weighting scheme with the criminal history variable included (.66 and .64 respectively), representing low, but still significant, levels of predictive value accuracy. When the criminal history variable was excluded, this level dropped to .60 for the construction sample and .61 for the reliability sample, which suggests that not only is criminal history important to predicting diversion success, but also that there are important predictors to success that were not identified.

Based on the AUC's, the ranked-weighted checklist was explored further using chisquare analyses in order to determine the distribution of scores that would be of most use in a practical setting. The probabilities associated with the three collapsed categories of scores (low success, moderate success, and high success) were somewhat consistent with expectations. Specifically, whereas there was a significantly lower proportion of successful divertees within the low success category, there was a significantly higher proportion of successful divertees within the high success category (development sample only). That this checklist was able to predict diversion success at better than chance levels in this sample suggests that it is possible to create a screening tool that could be used to help better evaluate the likelihood of program completion and, more important, guide court workers in terms of determining what 
services/supports could contribute to a client's success. Rather than conceiving of this checklist as a means to exclude people from diversion programming, it could be useful to think of it as a mechanism that would be useful in guiding decision-making to avoid selection biases. Given that some evidence suggests that older, white females tend to be overrepresented in diversion samples (e.g., Hiday et al., 2013; Naples, Morris, \& Steadman, 2007) it could potentially be of use to have empirically-derived tools to help guide admission decisions. If further dynamic variables could be identified as important predictors of diversion success, the checklist could be additionally used to prioritize interventions during diversion programming. For example, if change in housing status (i.e., moving from homeless to housed) was shown to be empirically more important than finding a psychiatrist, then the scores and responses on the checklist could provide something of a map in terms of planning out the services/interventions required during an individual's diversion programming.

There is the question about whether this checklist would perform at an acceptable level within another sample, or whether there would be difficulties with generalizability. Diversion programs differ greatly across locations in terms of the client characteristics and the severity of offending that is divertable. Despite the fact that the current set of studies utilized a large multisite sample, further checklist development would need to be conducted in additional samples from different provinces/regions, settings (rural vs. urban), and client characteristics in order to be better assured that the variables identified are representative of diversion programming in general. The results also underscore the importance of collecting information on criminal history at all court sites, as this has been shown to be a consistent and important predictor of recidivism and outcomes in diversion samples. 


\section{Limitations}

Some of the strengths of the current set of studies included the fact that it used a large, multisite sample, and also that it was one of the few studies that has been conducted within a Canadian context. However, research on mental health diversion necessarily uses clinical data that, in many instances, were obtained from front-line diversion programs. As such, there are limitations that need to be noted. In addition to the missing data noted in the method sections of each study, there is the possibility that data were initially entered incorrectly by the court workers or that there was some inconsistency in how the variables were interpreted by each court worker. It is hoped these limitations were minimized by the extensive data cleaning that was conducted. Furthermore, all court workers would have had training in entering data into the common dataset and had access to a manual that defined all the variables and operational definitions.

An additional data quality issue is the possibility that some of the offences were coded as less severe than they actually were, leading to lower scores on the violent and nonviolent Cormier-Lang variables. Because there was no access to police reports when coding these variables, it was decided to err on the side of coding offences as the lowest level of severity if there was any uncertainty. For example, because sexual offences were not specified in the dataset, these were all coded at the lowest possible level of severity according to the CormierLang severity coding scheme. It would have been informative to have had access to the police reports associated with the offences, however, because it would have allowed a better understanding of the range and severity of offences that were successfully diverted.

Finally, there were also a number of limitations in regard to variables that were available to study. In future, research would ideally have access to a number of additional variables in 
order to more thoroughly examine diversion success. First, although it was possible to examine program completion, there were no data available on recidivism. This would have been helpful to have, as it would have allowed for the examination of whether or not the predictors of diversion completion identified in Study 3 also predict recidivism, or if recidivism is predicted by a different set of variables. Second, it would have been useful to have information on measures of change. If the court workers administered a brief screening tool at the beginning of program entry and again at exit, it would allow for a quantifiable measure of whether psychiatric symptomatology was reduced over the course of program involvement. Being diligent about filling out the information relating to linkages to services is also an important future consideration, as there is still some question about what works in diversion - specifically, what the important program factors are that contribute to successful outcomes. Is it service linking, the intensive supervision, the reduction in psychiatric symptomatology? Multiple measures of change would help to answer this question. Finally, it would be very helpful to explicitly measure a client's level of social/family support; for example, collecting data on whether the client has family that is involved in their treatment and their lives, and whether the client has supportive friends. Although it is always difficult to implement additional data collection in a court support setting due to time constraints and additional workload burden on the part of the front line workers, this extra information would allow for a more complete understanding of the factors that contribute to successful diversion outcomes, and whether these successful outcomes are linked to a reduction in recidivism over significant periods of time. 


\section{Conclusion}

Despite the fact that mental health diversion is becoming an increasingly popular intervention, Canadian research on this topic is quite scarce. The current set of studies examined multisite mental health diversion programming within the Greater Toronto Area, with the aim of understanding the predictors associated with diversion success and whether these predictors of diversion completion could be combined to create a checklist that could potentially be used as a screening tool within a mental health diversion program setting. The results indicate that it was possible to predict diversion outcome with a good level of accuracy, and although the subsequently created checklist had lower levels of accuracy, it was still of use in predicting diversion success at better than chance levels. 
Table 1

Descriptions, Categories, and Operational Definitions of All Variables.

\begin{tabular}{|c|c|c|c|c|}
\hline Domain & Variable & Description & Category & Operational Definition \\
\hline Demographic & Age & Age of client in years. & & $\begin{array}{l}\text { Calculated from date of } \\
\text { admission. }\end{array}$ \\
\hline Demographic & Gender & $\begin{array}{l}\text { Biological sex of client. } \\
\text { According to database } \\
\text { manual, this information } \\
\text { was usually obtained from } \\
\text { record of arrest. }\end{array}$ & Male & \\
\hline Psychosocial & & & $\begin{array}{l}\text { Supported/Non- } \\
\text { Profit/Subsidized }\end{array}$ & $\begin{array}{l}\text { Any type of housing that } \\
\text { includes some type of } \\
\text { subsidization, supervision, } \\
\text { or assistance. See Appendix } \\
\text { for examples. }\end{array}$ \\
\hline \multirow[t]{3}{*}{ Psychosocial } & $\begin{array}{l}\text { Living Situation at } \\
\text { baseline and exit }\end{array}$ & $\begin{array}{l}\text { Who client resides with at } \\
\text { baseline or exit. }\end{array}$ & Alone & Client lives alone. \\
\hline & & & Relatives & $\begin{array}{l}\text { Client lives with } \\
\text { spouse/partner, parents, } \\
\text { children, or other relatives. }\end{array}$ \\
\hline & & & Non-Relatives & $\begin{array}{l}\text { Client lives with non-related } \\
\text { others, either in a group } \\
\text { setting or shared } \\
\text { accommodations. }\end{array}$ \\
\hline
\end{tabular}




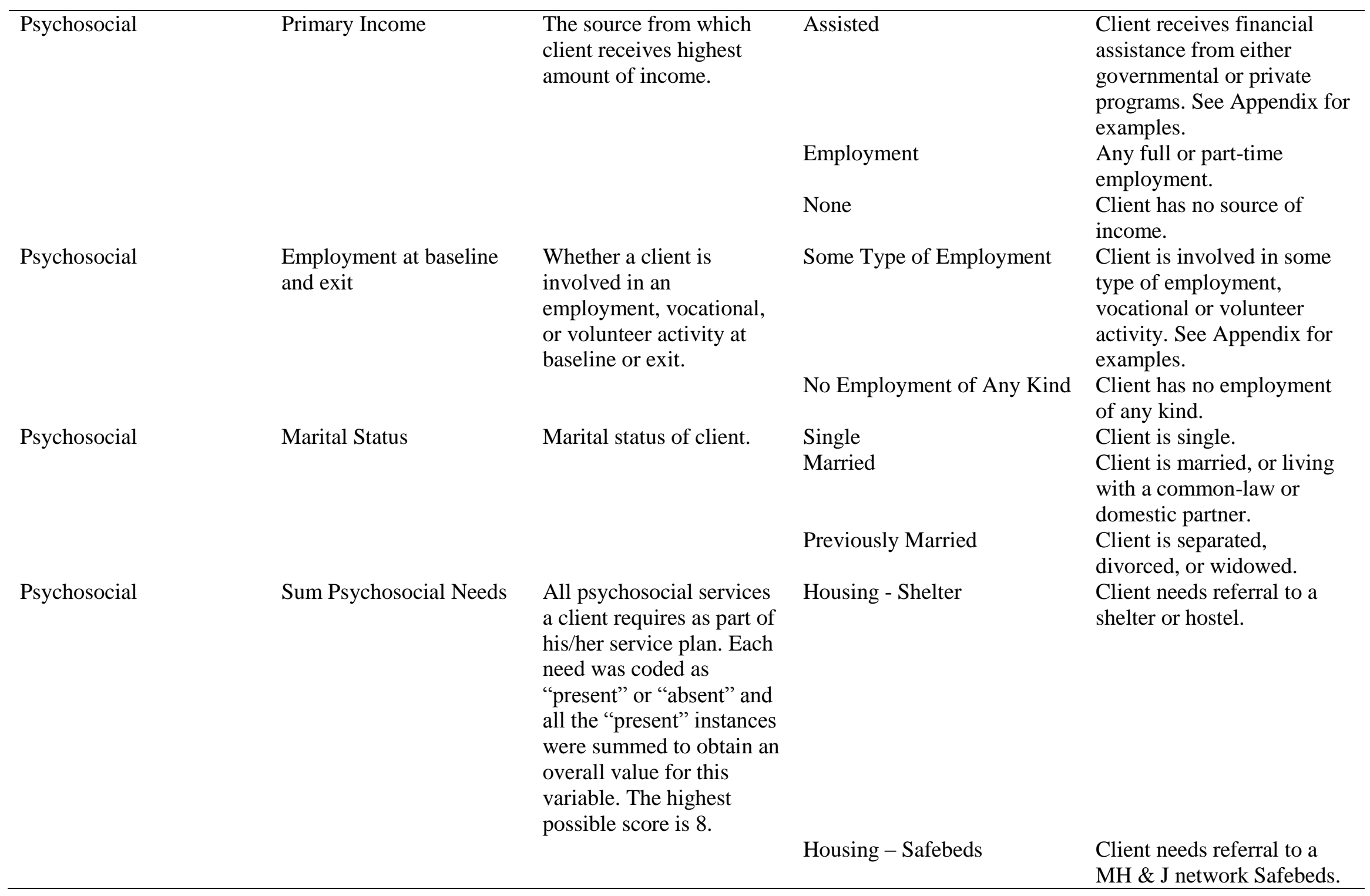


Housing - Other

Court Case Management

Case Management - Other

Self Help/Support Groups

Financial

Immigration
Client needs referral to a

type of housing other than a

shelter (e.g., boarding

house, subsidized

apartment, etc.). This

variable also includes non-

justice mental health crisis

beds.

Client needs a referral to a court support program case manager.

Client needs referral to case management outside the court support program.

Client needs referral to support groups, community centres, or drop-in centres. Does not include referrals for groups relating to substance abuse.

Client needs assistance in obtaining financial support such as Ontario Works,

CPP, EI, etc.

Client needs referral to nonmental health service relating to

immigration/settlement.

Referral to immigration

lawyer is recorded under Legal Needs. 


\begin{tabular}{|c|c|c|c|c|}
\hline \multirow[t]{6}{*}{ Psychosocial } & $\begin{array}{l}\text { Sum Psychosocial } \\
\text { Presenting Issues }\end{array}$ & $\begin{array}{l}\text { The psychosocial reasons } \\
\text { a client is seeking services } \\
\text { and the issues to be } \\
\text { addressed during the } \\
\text { reporting period. Each } \\
\text { issue was scored as } \\
\text { "present" or "absent" and } \\
\text { all the "present" issues } \\
\text { were summed to obtain an } \\
\text { overall value on this } \\
\text { variable. The highest } \\
\text { possible score is } 6 .\end{array}$ & Activities of Daily Living & $\begin{array}{l}\text { Client needs assistance to } \\
\text { perform activities of daily } \\
\text { living such as meal } \\
\text { preparation, personal } \\
\text { hygiene, managing } \\
\text { medications, etc. }\end{array}$ \\
\hline & & & Educational & $\begin{array}{l}\text { Client needs assistance with } \\
\text { continuing or upgrading } \\
\text { their education. }\end{array}$ \\
\hline & & & $\begin{array}{l}\text { Occupational/Employment/ } \\
\text { Vocational }\end{array}$ & $\begin{array}{l}\text { Client needs assistance with } \\
\text { changing or improving their } \\
\text { employment. }\end{array}$ \\
\hline & & & Housing & $\begin{array}{l}\text { Client needs assistance to } \\
\text { change or improve their } \\
\text { housing. }\end{array}$ \\
\hline & & & Financial & $\begin{array}{l}\text { Client needs assistance with } \\
\text { matters regarding financial } \\
\text { management. }\end{array}$ \\
\hline & & & Relationships & $\begin{array}{l}\text { Client needs assistance in } \\
\text { regards to stress from issues } \\
\text { in social or family } \\
\text { relationships. }\end{array}$ \\
\hline \multirow[t]{2}{*}{ Clinical } & Primary Diagnosis & $\begin{array}{l}\text { Client's primary diagnosis } \\
\text { as per either a licensed } \\
\text { mental health professional } \\
\text { or self-reported. }\end{array}$ & Psychotic Disorder & $\begin{array}{l}\text { Client has a primary } \\
\text { diagnosis of schizophrenia } \\
\text { or schizoaffective disorder. }\end{array}$ \\
\hline & & & Mood/Anxiety Disorder & $\begin{array}{l}\text { Client has a primary } \\
\text { diagnosis of a mood or } \\
\text { anxiety disorder. See } \\
\text { Appendix for examples. }\end{array}$ \\
\hline
\end{tabular}




\section{Personality Disorder}

Substance Abuse

Other

None

\section{Clinical}

\section{Clinical}

Clinical

\section{Primary Diagnosis Mood/Anxiety}

Primary Diagnosis Psychotic

Any Substance Use Issues
Whether client has a primary diagnosis of a mood/anxiety disorder.

Whether client has a primary diagnosis of psychotic disorder.

Whether a client has any substance use issues.
Client has a primary diagnosis of personality disorder.

Client has a primary diagnosis of substance abuse.

Client has a primary

diagnosis other than a psychotic, mood/anxiety, personality, or substance abuse disorder. See Appendix for examples.

Client has a primary diagnosis of a mood/anxiety disorder. See Appendix for examples.

Client has a primary diagnosis of schizophrenia or schizoaffective disorder.

Composite variable. If yes, client has either a primary substance use disorder, or additional substance use disorder (could be selfreported). 


\begin{tabular}{|c|c|c|c|c|}
\hline \multirow[t]{4}{*}{ Clinical } & Sum Clinical Needs & $\begin{array}{l}\text { All clinical services a } \\
\text { client requires as part of } \\
\text { his/her service plan. Each } \\
\text { need was coded as } \\
\text { "present" or "absent" and } \\
\text { all the "present" instances } \\
\text { were summed to obtain an } \\
\text { overall value for this } \\
\text { variable. The highest } \\
\text { possible score is } 5 \text {. }\end{array}$ & Psychiatrist & $\begin{array}{l}\text { Whether client needs a } \\
\text { referral to psychiatrist for } \\
\text { treatment or follow-up. }\end{array}$ \\
\hline & & & Substance Abuse Services & $\begin{array}{l}\text { Client needs referral to a } \\
\text { community or hospital- } \\
\text { based substance abuse } \\
\text { program. }\end{array}$ \\
\hline & & & Rehab & $\begin{array}{l}\text { Client needs referral to a } \\
\text { rehabilitation program other } \\
\text { than substance abuse. E.g., } \\
\text { eating disorder program, } \\
\text { anger management } \\
\text { program.* Does include } \\
\text { some programs that could } \\
\text { be considered psychosocial. }\end{array}$ \\
\hline & & & ACTT & $\begin{array}{l}\text { Client needs referral to an } \\
\text { Assertive Community } \\
\text { Treatment Team. }\end{array}$ \\
\hline
\end{tabular}




\begin{tabular}{|c|c|c|c|c|}
\hline \multirow[t]{2}{*}{ Clinical } & $\begin{array}{l}\text { Sum Clinical Presenting } \\
\text { Issues }\end{array}$ & $\begin{array}{l}\text { The clinical reasons a } \\
\text { client is seeking services, } \\
\text { and the issues to be } \\
\text { addressed during the } \\
\text { reporting period. Each } \\
\text { issue was scored as } \\
\text { "present" or "absent" and } \\
\text { all instances of "present" } \\
\text { were summed to obtain a } \\
\text { total value for this } \\
\text { variable. The highest } \\
\text { possible score on this } \\
\text { variable is } 4 \text {. }\end{array}$ & Threat/Others Suicide & $\begin{array}{l}\text { Client is a threat/danger to } \\
\text { themselves or others. }\end{array}$ \\
\hline & & & $\begin{array}{l}\text { Specific Symptoms } \\
\text { Significant Mental Illness }\end{array}$ & $\begin{array}{l}\text { Client is experiencing issues } \\
\text { surrounding psychiatric } \\
\text { symptoms, symptom } \\
\text { management, or treatment } \\
\text { management/compliance. }\end{array}$ \\
\hline Criminological & $\begin{array}{l}\text { Prior Criminal History } \\
\text { Composite }\end{array}$ & $\begin{array}{l}\text { Refers to whether a client } \\
\text { has a known prior } \\
\text { criminal history. }\end{array}$ & Yes & $\begin{array}{l}\text { This variable was coded } \\
\text { from both the "previous } \\
\text { sentencing" and "previous } \\
\text { offences" variables. An } \\
\text { individual was coded as } \\
\text { having a criminal history if } \\
\text { the client had a value other } \\
\text { than } 0 \text { in either of these } \\
\text { categories. }\end{array}$ \\
\hline
\end{tabular}


Criminal history was coded as "No" if there was a 0 in

Criminological

Total Index Offences

Refers to each client's total number of current/index offences.

\section{Criminological}

Criminological

Criminological
Cormier-Lang Severity of Violent Index Offences

Legal Needs
Cormier-Lang Severity of Nonviolent Index

Offences

This variable is a measure

of the severity of the

client's index nonviolent offences.

This variable is a measure of the severity of the client's index violent offences.

Whether a client needs to Yes be linked to legal services. both categories.

Both violent and nonviolent index offences were summed together to obtain this variable.

For each client, all the nonviolent index offences were scored using the CormierLang severity scale. These scores were then summed in order to obtain a nonviolent severity score for each client.

For each client, all the violent index offences were scored using the CormierLang severity scale. These scores were then summed in order to obtain a violent severity score for each client.

Client needs to be linked to services other than duty counsel. Includes links to legal aid, immigration lawyers, civil lawyers. Client does not need to be linked to legal services. 


\begin{tabular}{|c|c|c|c|c|}
\hline Criminological & Legal Status at Referral & $\begin{array}{l}\text { Refers to the latest stage } \\
\text { in the legal process that a } \\
\text { client has reached. }\end{array}$ & $\begin{array}{l}\text { Awaiting Bail } \\
\text { Awaiting Trial } \\
\text { Awaiting Sentencing }\end{array}$ & $\begin{array}{l}\text { It was possible that a client } \\
\text { fell into more than one } \\
\text { category of this variable. As } \\
\text { such, legal status at referral } \\
\text { was operationalized as the } \\
\text { latest stage in the legal } \\
\text { process that a client had } \\
\text { reached, if more than one } \\
\text { stage was indicated. }\end{array}$ \\
\hline Procedural & Longest Length of Stay & $\begin{array}{l}\text { Longest length of time in } \\
\text { Months that client spent } \\
\text { in the program. }\end{array}$ & & $\begin{array}{l}\text { Longest length of stay was } \\
\text { calculated as the time period } \\
\text { between a client's first } \\
\text { contact with the program } \\
\text { and his/her date of } \\
\text { discharge from the program. }\end{array}$ \\
\hline
\end{tabular}


Table 2

Study 1 Univariate Relationships Between all Variables and Program Knowledge of Clients Criminal Histories.

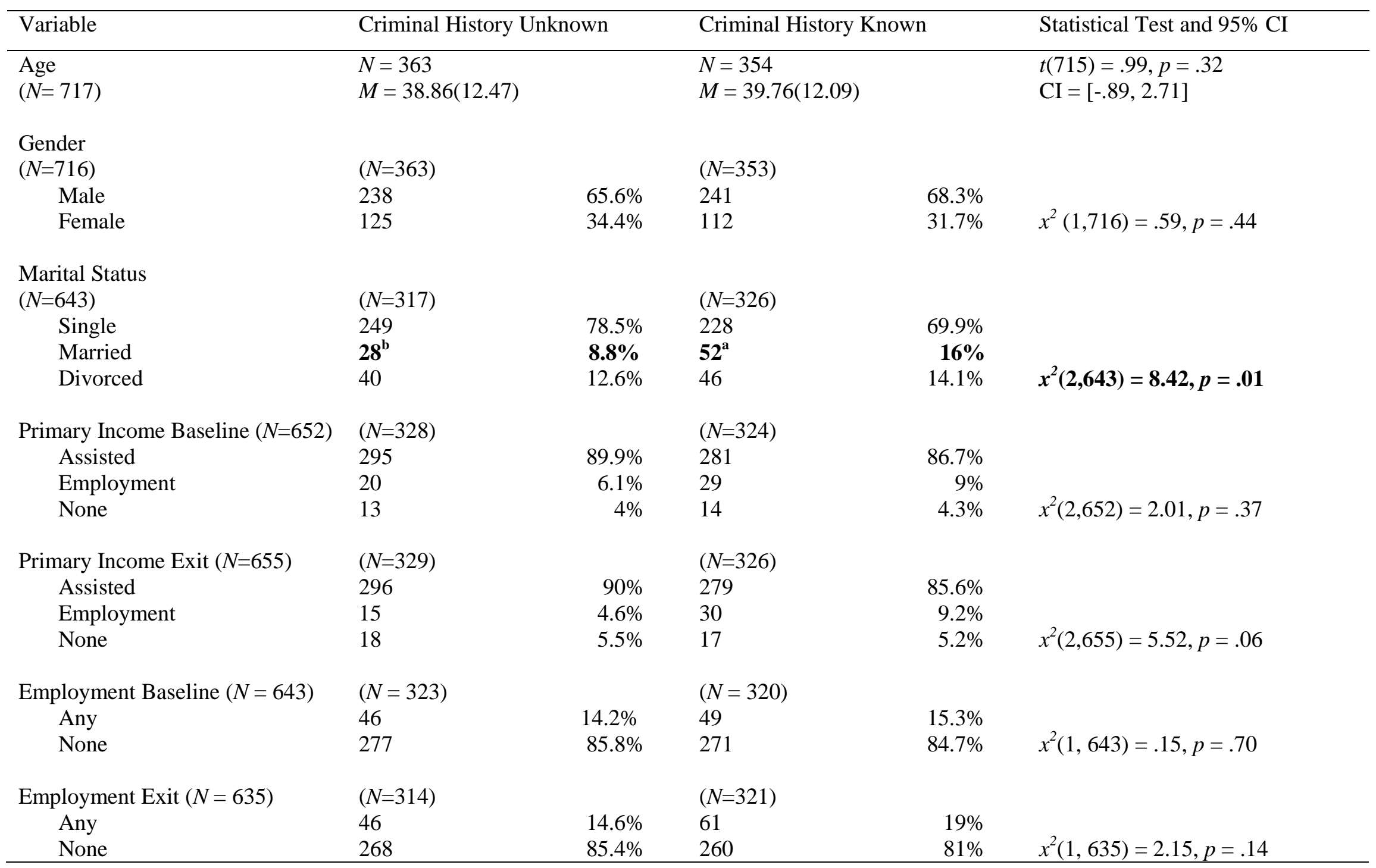




\begin{tabular}{|c|c|c|c|c|c|}
\hline Living Situation Baseline $(N=689)$ & $(N=348)$ & & $(N=341)$ & & \\
\hline Self/Alone & $156^{\mathrm{a}}$ & $44.8 \%$ & $95^{b}$ & $27.9 \%$ & \\
\hline Relatives & 87 & $25 \%$ & 112 & $32.8 \%$ & \\
\hline Non-Relatives & 105 & $30.2 \%$ & 134 & $39.3 \%$ & $x^{2}(2,689)=21.41, p<.001$ \\
\hline Living Situation Exit $(N=689)$ & $(N=346)$ & & $(N=343)$ & & \\
\hline Self/Alone & $164^{\mathrm{a}}$ & $47.4 \%$ & $109^{b}$ & $31.8 \%$ & \\
\hline Relatives & $84^{b}$ & $24.3 \%$ & $143^{\mathrm{a}}$ & $41.7 \%$ & \\
\hline Non-Relatives & 98 & $28.3 \%$ & 91 & $26.5 \%$ & $x^{2}(2,689)=26.66, p<.001$ \\
\hline Housing Type Baseline $(N=691)$ & $(N=347)$ & & $(N=344)$ & & \\
\hline Mrkt Rent & 108 & $31.1 \%$ & 142 & $41.3 \%$ & \\
\hline Supported/Nonprofit & 138 & $39.8 \%$ & 103 & $29.9 \%$ & \\
\hline Homeless & $76^{\mathrm{a}}$ & $21.9 \%$ & $39^{b}$ & $11.3 \%$ & \\
\hline Institutional & $25^{b}$ & $7.2 \%$ & $60^{\mathrm{a}}$ & $17.4 \%$ & $x^{2}(3,691)=36.01, p<.001$ \\
\hline Housing Type Exit $(N=647)$ & $(N=321)$ & & $(N=326)$ & & \\
\hline Mrkt Rent & $104^{b}$ & $32.4 \%$ & $154^{\mathrm{a}}$ & $47.2 \%$ & \\
\hline Supported/Nonprofit & 135 & $42.1 \%$ & 135 & $41.4 \%$ & \\
\hline Homeless & $61^{\mathrm{a}}$ & $19 \%$ & $\mathbf{2 6}^{\mathrm{b}}$ & $8 \%$ & \\
\hline Institutional & 21 & $6.5 \%$ & 11 & $3.4 \%$ & $x^{2}(3,647)=26.86, p<.001$ \\
\hline Primary Diagnosis $(N=689)$ & $(N=343)$ & & $(N=346)$ & & \\
\hline Psychotic & 162 & $47.2 \%$ & 134 & $38.7 \%$ & \\
\hline Mood/Anxiety & $130^{b}$ & $37.9 \%$ & $172^{\mathrm{a}}$ & $49.7 \%$ & \\
\hline Personality & 6 & $1.7 \%$ & 4 & $1.2 \%$ & \\
\hline Substance Abuse & 15 & $4.4 \%$ & 9 & $2.6 \%$ & \\
\hline Other & 28 & $8.2 \%$ & 24 & $6.9 \%$ & \\
\hline None & 2 & $0.6 \%$ & 3 & $0.9 \%$ & $x^{2}(5,689)=10.88, p=.05$ \\
\hline $\begin{array}{l}\text { Any Substance Use Disorder }(N= \\
690)\end{array}$ & $(N=344)$ & & $(N=346)$ & & \\
\hline Yes & $125^{\mathrm{a}}$ & $36.3 \%$ & $\mathbf{7 5}^{\mathrm{b}}$ & $21.7 \%$ & \\
\hline No & 219 & $63.7 \%$ & 271 & $78.3 \%$ & $x^{2}(1,690)=18.01, p<.001$ \\
\hline
\end{tabular}




\begin{tabular}{|c|c|c|c|c|c|}
\hline Sum Clinical Needs $(N=676)$ & $\begin{array}{l}(N=333) \\
M=.60(.83)\end{array}$ & & $\begin{array}{l}(N=343) \\
M=.53(.76)\end{array}$ & & $\begin{array}{l}t(674)=-1.14, p=.25 \\
\mathrm{CI}=[-.19, .05]\end{array}$ \\
\hline Sum Psychosocial Needs $(N=676)$ & $\begin{array}{l}(N=333) \\
M=.75(.89)\end{array}$ & & $\begin{array}{l}(N=343) \\
M=.76(1.02)\end{array}$ & & $\begin{array}{l}t(666.47)=.18, p=.86^{\mathrm{c}} \\
\mathrm{CI}=[-.13, .16]\end{array}$ \\
\hline $\begin{array}{l}\text { Legal Needs }(N=676) \\
\text { Yes } \\
\text { No }\end{array}$ & $\begin{array}{l}(N=333) \\
52 \\
281\end{array}$ & $\begin{array}{l}15.6 \% \\
84.4 \%\end{array}$ & $\begin{array}{l}(N=343) \\
57 \\
286\end{array}$ & $\begin{array}{l}16.6 \% \\
83.4 \%\end{array}$ & $x^{2}(1,676)=.13, p=.72$ \\
\hline $\begin{array}{l}\text { Longest Length of Stay in Months } \\
(N=718)\end{array}$ & $\begin{array}{l}(N=364) \\
M=6.53(4.97)\end{array}$ & & $\begin{array}{l}(N=354) \\
M=5.94(4.50)\end{array}$ & & $\begin{array}{l}t(712.42)=-1.69, p=.09^{\mathrm{c}} \\
\mathrm{CI}=[-1.29, .09]\end{array}$ \\
\hline $\begin{array}{l}\text { Presenting Issues Clinical ( } N= \\
712)\end{array}$ & $\begin{array}{l}(N=361) \\
M=1.12(.74)\end{array}$ & & $\begin{array}{l}(N=351) \\
M=1.28(.74)\end{array}$ & & $\begin{array}{l}t(710)=2.89, p=.004 \\
C I=[.05, .27]\end{array}$ \\
\hline $\begin{array}{l}\text { Presenting Issues Psychosocial } \\
(N=712)\end{array}$ & $\begin{array}{l}(N=361) \\
M=.84(.97)\end{array}$ & & $\begin{array}{l}(N=351) \\
M=.90(1.04)\end{array}$ & & $\begin{array}{l}t(703.24)=.73, p=.46^{\mathrm{c}} \\
\mathrm{CI}=[-.09, .20]\end{array}$ \\
\hline $\begin{array}{l}\text { Percent with Presenting Legal } \\
\text { Issues }(N=712)\end{array}$ & $\begin{array}{l}(N=361) \\
352\end{array}$ & $97.5 \%$ & $\begin{array}{l}(N=351) \\
342\end{array}$ & $97.4 \%$ & $x^{2}(1,712)=.004, p=.95$ \\
\hline Cormier-Lang Violent $(N=703)$ & $\begin{array}{l}(N=353) \\
M=1.30(2.01)\end{array}$ & & $\begin{array}{l}(N=350) \\
M=1.54(2.08)\end{array}$ & & $\begin{array}{l}t(701)=1.59, p=.11 \\
\mathrm{CI}=[-.06, .55]\end{array}$ \\
\hline $\begin{array}{l}\text { Cormier-Lang Nonviolent } \\
(N=703)\end{array}$ & $\begin{array}{l}(N=353) \\
M=2.64(2.90)\end{array}$ & & $\begin{array}{l}(N=350) \\
M=2.39(2.61)\end{array}$ & & $\begin{array}{l}t(701)=-1.22, p=.22 \\
\mathrm{CI}=[-.66, .15]\end{array}$ \\
\hline Total Current Offences $(N=704)$ & $\begin{array}{l}(N=354) \\
M=2.54(2.10)\end{array}$ & & $\begin{array}{l}(N=350) \\
M=2.41(1.92)\end{array}$ & & $\begin{array}{l}t(702)=-.84, p=.40 \\
\mathrm{CI}=[-.43, .17]\end{array}$ \\
\hline
\end{tabular}




\begin{tabular}{|c|c|c|c|c|c|}
\hline Court Site $(N=704)$ & $(N=357)$ & & $(N=347)$ & & \\
\hline 102/Old City Hall & $182^{\mathrm{a}}$ & $51 \%$ & $90^{b}$ & $25.9 \%$ & \\
\hline Metro West & $6^{b}$ & $1.7 \%$ & $48^{\mathrm{a}}$ & $13.8 \%$ & \\
\hline Metro East & $9^{b}$ & $2.5 \%$ & $72^{\mathrm{a}}$ & $20.7 \%$ & \\
\hline College Park & $132^{\mathrm{a}}$ & $37 \%$ & $57^{b}$ & $16.4 \%$ & \\
\hline Metro North & $28^{b}$ & $7.8 \%$ & $80^{\mathrm{a}}$ & $23.1 \%$ & $x^{2}(4,704)=167.47, p<.001$ \\
\hline Legal Status at Referral $(N=569)$ & $(N=275)$ & & $(N=294)$ & & \\
\hline Awaiting Bail & 18 & $6.5 \%$ & 14 & $4.8 \%$ & \\
\hline Awaiting Trial & 202 & $73.5 \%$ & 269 & $91.5 \%$ & \\
\hline Awaiting Sentencing & $55^{\mathrm{a}}$ & $20 \%$ & $11^{\mathrm{b}}$ & $3.7 \%$ & $x^{2}(2,569)=38.77, p<.001$ \\
\hline
\end{tabular}

Note. $\mathrm{CI}=$ confidence interval.

${ }^{\mathrm{a}}$ significantly larger proportion than expected, ${ }^{\mathrm{b}}$ significantly lower proportion than expected, ${ }^{\mathrm{c}}$ equal variances not assumed. 
Table 3

Study 1 Descriptive and Univariate Statistics Grouped by Overall Sample, Successful Diversion, and Unsuccessful Diversion.

\begin{tabular}{|c|c|c|c|c|c|c|}
\hline Variable & Total Sample & \multicolumn{2}{|l|}{ Success } & \multicolumn{2}{|c|}{ No Success } & Statistical Test and 95\% CI \\
\hline $\begin{array}{l}\text { Age } \\
(N=717)\end{array}$ & $\begin{array}{l}M=39.30(12.28) \\
\text { Range }=18-80\end{array}$ & \multicolumn{2}{|c|}{$\begin{array}{l}M=40.17(12.56) \\
(N=483)\end{array}$} & \multicolumn{2}{|c|}{$\begin{array}{l}M=37.37(11.62) \\
(N=224)\end{array}$} & $\begin{array}{l}t(705)=2.82, p=.005 \\
\text { CI }=[.85,4.74]\end{array}$ \\
\hline \multicolumn{7}{|l|}{ Gender } \\
\hline Male & $66.7 \%$ & 318 & $66 \%$ & 153 & $68.3 \%$ & \\
\hline Female & $33 \%$ & 164 & $34 \%$ & 71 & $31.7 \%$ & $x^{2}(1,706)=.37, p=.54$ \\
\hline \multicolumn{7}{|l|}{ Marital Status } \\
\hline Single & $66.4 \%$ & 325 & $71.9 \%$ & 146 & $80.2 \%$ & \\
\hline Married & $11.1 \%$ & 62 & $13.7 \%$ & 18 & $9.9 \%$ & \\
\hline Widowed & $12 \%$ & 65 & $14.4 \%$ & 18 & $9.9 \%$ & $x^{2}(2,634)=4.71, p=.09$ \\
\hline \multicolumn{7}{|c|}{$\begin{array}{l}\text { Primary Income Baseline } \\
(N=652)\end{array}$} \\
\hline Assisted & $80.2 \%$ & 401 & $88.5 \%$ & 166 & $87.8 \%$ & \\
\hline Employment & $6.8 \%$ & 36 & $7.9 \%$ & 13 & $6.9 \%$ & \\
\hline None & $3.8 \%$ & 16 & $3.5 \%$ & 10 & $5.3 \%$ & $x^{2}(2,642)=1.23, p=.54$ \\
\hline \multicolumn{6}{|c|}{ Primary Income Exit } & \\
\hline Assisted & $80.1 \%$ & 397 & $86.9 \%$ & 169 & $89.9 \%$ & \\
\hline Employment & $6.3 \%$ & 36 & $7.9 \%$ & 9 & $4.8 \%$ & \\
\hline None & $4.9 \%$ & 24 & $5.3 \%$ & 10 & $5.3 \%$ & $x^{2}(2,645)=1.96, p=.37$ \\
\hline \multicolumn{7}{|c|}{ Employment Baseline } \\
\hline None & $76.3 \%$ & 384 & $84.4 \%$ & 157 & $87.2 \%$ & \\
\hline Any & $13.2 \%$ & 71 & $15.6 \%$ & 23 & $12.8 \%$ & $x^{2}(1,635)=.82, p=.37$ \\
\hline
\end{tabular}




\begin{tabular}{|c|c|c|c|c|c|c|}
\hline \multicolumn{7}{|l|}{$\begin{array}{l}\text { Employment Exit } \\
(N=635)\end{array}$} \\
\hline None & $73.5 \%$ & 368 & $81.4 \%$ & 153 & $87.4 \%$ & \\
\hline Any & $14.9 \%$ & 84 & $18.6 \%$ & 22 & $12.6 \%$ & $x^{2}(1,627)=3.25, p=.07$ \\
\hline \multicolumn{7}{|c|}{ Living Situation Baseline } \\
\hline Self/Alone & $35 \%$ & 172 & $36.1 \%$ & 75 & $36.9 \%$ & \\
\hline Relatives & $27.7 \%$ & 142 & $29.8 \%$ & 55 & $27.1 \%$ & \\
\hline Non-Relatives & $33.3 \%$ & 162 & $34.0 \%$ & 73 & $36.0 \%$ & $x^{2}(2,679)=.55, p=.76$ \\
\hline \multicolumn{7}{|l|}{ Living Situation Exit } \\
\hline Self/Alone & $38 \%$ & 194 & $40.2 \%$ & 76 & $38.6 \%$ & \\
\hline Relatives & $31.6 \%$ & 163 & $33.8 \%$ & 62 & $31.5 \%$ & \\
\hline Non-Relatives & $26.3 \%$ & 125 & $25.9 \%$ & 59 & $29.9 \%$ & $x^{2}(2,679)=1.16, p=.56$ \\
\hline \multicolumn{7}{|c|}{ Housing Type Baseline } \\
\hline Market Rent & $34.8 \%$ & 178 & $37.6 \%$ & 71 & $34.1 \%$ & \\
\hline Subsidized & $33.6 \%$ & 174 & $36.8 \%$ & 61 & $29.3 \%$ & \\
\hline Homeless & $16 \%$ & 67 & $14.2 \%$ & $47^{\mathrm{a}}$ & $22.6 \%$ & \\
\hline Institutional & $11.8 \%$ & 54 & $11.4 \%$ & 29 & $13.9 \%$ & $x^{2}(3,681)=9.70, p=.02$ \\
\hline $\begin{array}{l}\text { Housing Type Exit } \\
(N=647)\end{array}$ & & $(N=455)$ & & $(N=184)$ & & \\
\hline Market Rent & $35.9 \%$ & 188 & $41.3 \%$ & 68 & $37.0 \%$ & \\
\hline Subsidized & $37.6 \%$ & 209 & $45.9 \%$ & $57^{\mathrm{b}}$ & $31.0 \%$ & \\
\hline Homeless & $12.1 \%$ & $44^{b}$ & $9.7 \%$ & $4^{\mathrm{a}}$ & $23.4 \%$ & \\
\hline Institutional & $4.5 \%$ & 14 & $3.1 \%$ & $16^{\mathrm{a}}$ & $8.7 \%$ & $x^{2}(3,639)=34.53, p<.001$ \\
\hline
\end{tabular}




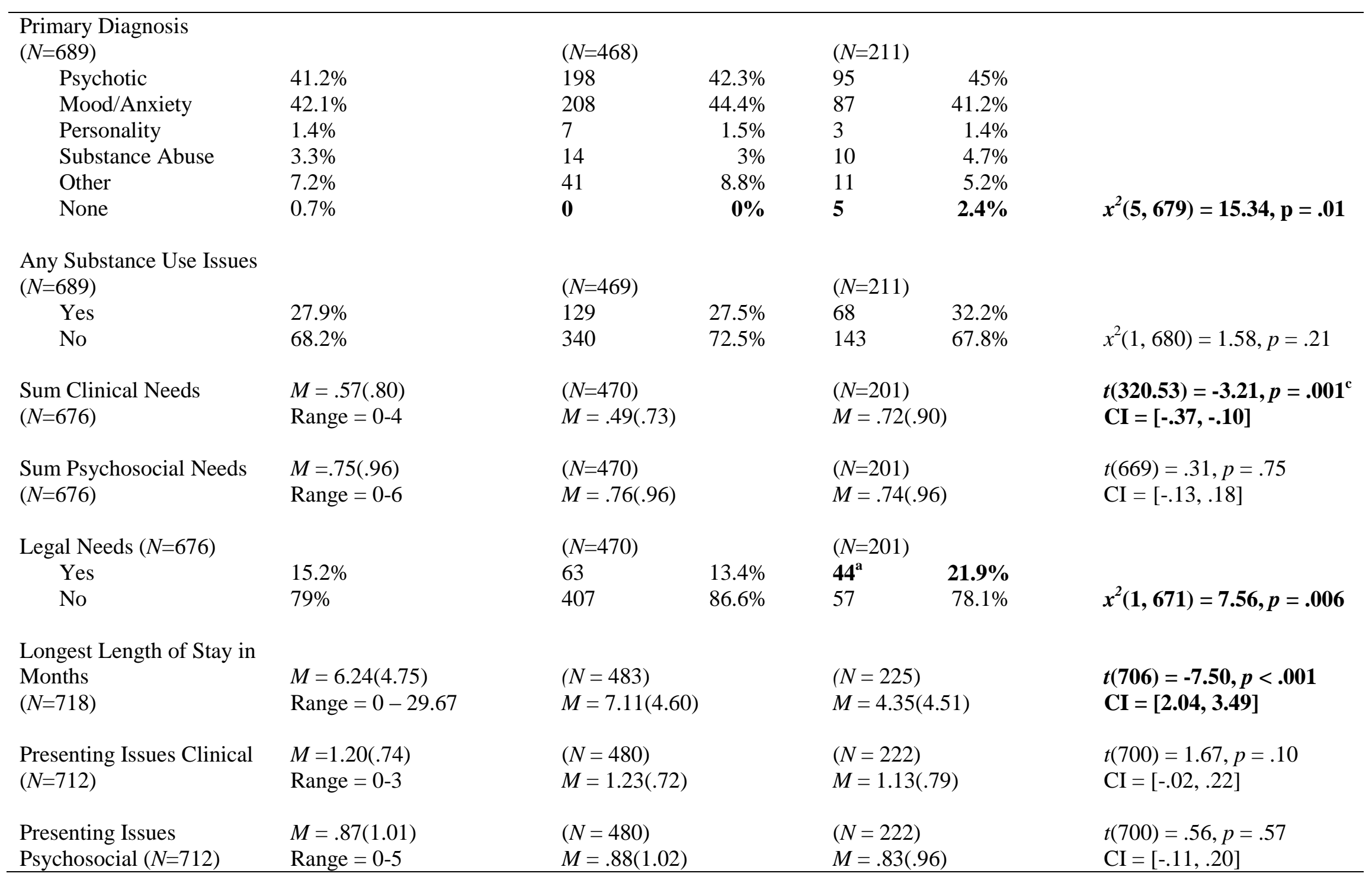




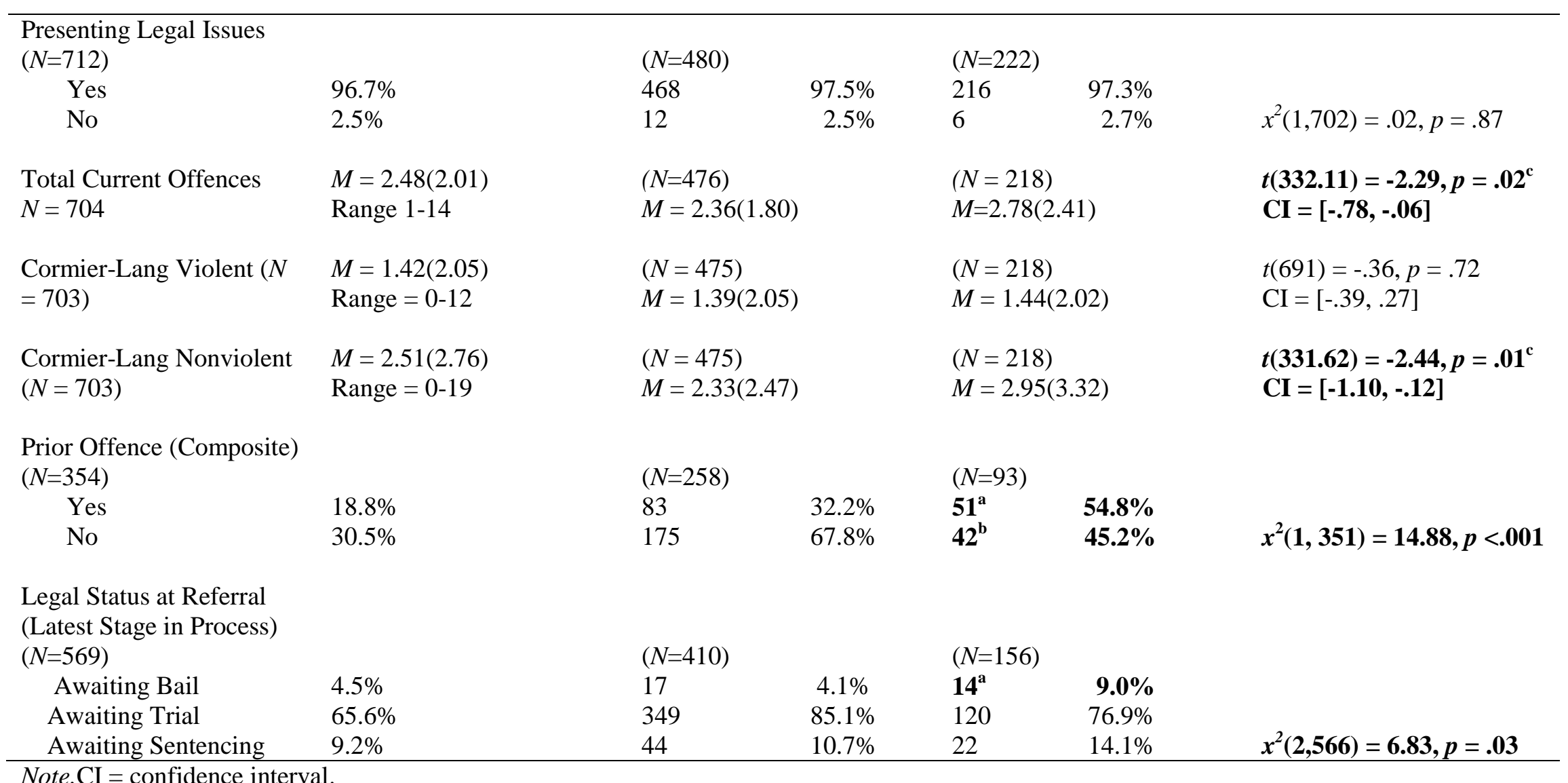

Note . $\mathrm{CI}=$ confidence interval.

${ }^{\mathrm{a}}$ significantly higher proportion than expected, ${ }^{\mathrm{b}}$ significantly lower proportion than expected, ${ }^{\mathrm{c}}$ equal variances not assumed. 
Table 4

Study 1 Univariate Relationships Between All Variables and Criminal History.

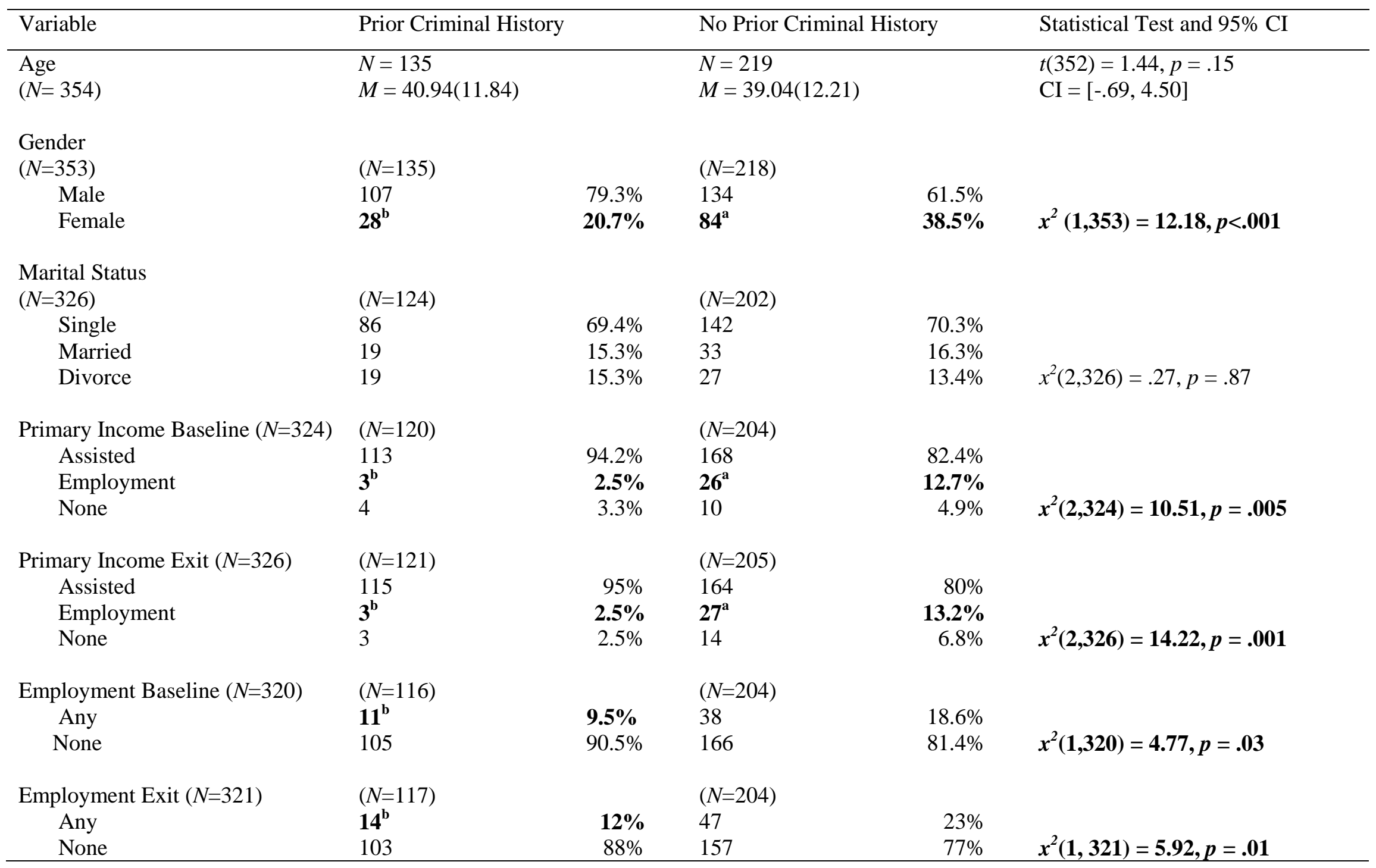




\begin{tabular}{|c|c|c|c|c|c|}
\hline Living Situation Baseline $(N=341)$ & $(N=128)$ & & $(N=213)$ & & \\
\hline Self/Alone & 46 & $35.9 \%$ & 49 & $23.0 \%$ & \\
\hline Relatives & $30^{b}$ & $23.4 \%$ & 82 & $38.5 \%$ & \\
\hline Non-Relatives & 52 & $40.6 \%$ & 82 & $38.5 \%$ & $x^{2}(2,341)=10.41, p=.005$ \\
\hline Living Situation Exit $(N=343)$ & $(N=127)$ & & $(N=216)$ & & \\
\hline Self/Alone & 46 & $36.2 \%$ & 63 & $29.2 \%$ & \\
\hline Relatives & 48 & $37.8 \%$ & 95 & $44 \%$ & \\
\hline Non-Relatives & 33 & $26.0 \%$ & 58 & $26.9 \%$ & $x^{2}(2,343)=2.01, p=.37$ \\
\hline Housing Type Baseline $(N=344)$ & $(N=130)$ & & $(N=214)$ & & \\
\hline Mrkt Rent & 43 & $33.1 \%$ & 99 & $46.3 \%$ & \\
\hline Supported/Nonprofit & 42 & $32.3 \%$ & 61 & $28.5 \%$ & \\
\hline Homeless & 19 & $14.6 \%$ & 20 & $9.3 \%$ & \\
\hline Institutional & 26 & $20 \%$ & 34 & $15.9 \%$ & $x^{2}(3,344)=6.56, p=.09$ \\
\hline Housing Type Exit $(N=326)$ & $(N=121)$ & & $(N=205)$ & & \\
\hline Mrkt Rent & 46 & $38 \%$ & 108 & $52.7 \%$ & \\
\hline Supported/Nonprofit & 56 & $46.3 \%$ & 79 & $38.5 \%$ & \\
\hline Homeless & $17^{\mathrm{a}}$ & $14 \%$ & 9 & $4.4 \%$ & \\
\hline Institutional & 2 & $1.7 \%$ & 9 & $4.4 \%$ & $x^{2}(3,326)=15.16, p=.002$ \\
\hline Primary Diagnosis $(N=346)$ & $(N=134)$ & & $(N=212)$ & & \\
\hline Psychotic & 61 & $45.4 \%$ & 73 & $34.4 \%$ & \\
\hline Mood/Anxiety & 60 & $44.8 \%$ & 112 & $52.8 \%$ & \\
\hline Personality & 1 & $0.7 \%$ & 3 & $1.4 \%$ & \\
\hline Substance Abuse & 5 & $3.7 \%$ & 4 & $1.9 \%$ & \\
\hline Other & 5 & $3.7 \%$ & 19 & $9 \%$ & \\
\hline None & 2 & $1.5 \%$ & 1 & $0.5 \%$ & $x^{2}(5,346)=9.29, p=.10$ \\
\hline $\begin{array}{l}\text { Any Substance Use Issues }(N= \\
346)\end{array}$ & $(N=134)$ & & $(N=212)$ & & \\
\hline Yes & $\mathbf{4 3}^{\mathrm{a}}$ & $32.2 \%$ & $\mathbf{3 2}^{\mathbf{b}}$ & $15.1 \%$ & \\
\hline No & 91 & $67.9 \%$ & 180 & $84.9 \%$ & $x^{2}(1,346)=13.97, p<.001$ \\
\hline
\end{tabular}




\begin{tabular}{|c|c|c|c|c|c|}
\hline Sum Clinical Needs $(N=343)$ & $\begin{array}{l}(N=128) \\
M=.63(.80)\end{array}$ & & $\begin{array}{l}(N=215) \\
M=.47(.73)\end{array}$ & & $\begin{array}{l}t(248.45)=1.73, p=.08^{\mathrm{c}} \\
\mathrm{CI}=[-.02, .32]\end{array}$ \\
\hline Sum Psychosocial Needs $(N=343)$ & $\begin{array}{l}(N=128) \\
M=.71(.99)\end{array}$ & & $\begin{array}{l}(N=215) \\
M=.79(1.04)\end{array}$ & & $\begin{array}{l}t(341)=-.70, p=.49 \\
C I=[-.30, .14]\end{array}$ \\
\hline $\begin{array}{l}\text { Legal Needs }(N=343) \\
\text { Yes } \\
\text { No }\end{array}$ & $\begin{array}{l}(N=128) \\
22 \\
106\end{array}$ & $\begin{array}{l}17.2 \% \\
82.8 \%\end{array}$ & $\begin{array}{l}(N=215) \\
35 \\
180\end{array}$ & $\begin{array}{l}16.3 \% \\
83.7 \%\end{array}$ & $x^{2}(1,343)=.05, p=.83$ \\
\hline $\begin{array}{l}\text { Longest Length Of Stay in Months } \\
(N=354)\end{array}$ & $\begin{array}{l}M=5.93(4.80) \\
(N=135)\end{array}$ & & $\begin{array}{l}M=5.94(4.32) \\
(N=219)\end{array}$ & & $\begin{array}{l}t(352)=-.003, p=1.00 \\
\text { CI }[-1.00, .97]\end{array}$ \\
\hline $\begin{array}{l}\text { Presenting Issues Clinical ( } N= \\
\text { 351) }\end{array}$ & $\begin{array}{l}(N=134) \\
M=1.32(.85)\end{array}$ & & $\begin{array}{l}(N=217) \\
M=1.26(.67)\end{array}$ & & $\begin{array}{l}t(235.32)=.67, p=.50^{\mathrm{c}} \\
\mathrm{CI}=[-.11, .23]\end{array}$ \\
\hline $\begin{array}{l}\text { Presenting Issues Psychosocial } \\
(N=351)\end{array}$ & $\begin{array}{l}(N=134) \\
M=.91(.91)\end{array}$ & & $\begin{array}{l}(N=217) \\
M=.89(1.11)\end{array}$ & & $\begin{array}{l}t(322.37)=.15, p=.88^{\mathrm{c}} \\
\mathrm{CI}=[-.20, .23]\end{array}$ \\
\hline $\begin{array}{l}\text { Percent with presenting Legal } \\
\text { Issues }(N=351)\end{array}$ & $\begin{array}{l}(N=134) \\
128\end{array}$ & $95.5 \%$ & $\begin{array}{l}(N=217) \\
214\end{array}$ & $98.6 \%$ & $x^{2}(1,351)=3.18, p=.07$ \\
\hline Cormier-Lang Violent $(N=350)$ & $\begin{array}{l}(N=132) \\
M=1.17(1.99)\end{array}$ & & $\begin{array}{l}(N=218) \\
M=1.77(2.10)\end{array}$ & & $\begin{array}{l}t(348)=-2.60, p=.01 \\
C I=[-1.04,-.14]\end{array}$ \\
\hline $\begin{array}{l}\text { Cormier-Lang Nonviolent } \\
(N=350)\end{array}$ & $\begin{array}{l}(N=132) \\
M=2.88(2.73)\end{array}$ & & $\begin{array}{l}(N=218) \\
M=2.09(2.50)\end{array}$ & & $\begin{array}{l}t(348)=2.77, p=.01 \\
C I=[.23,1.35]\end{array}$ \\
\hline Total Current Offences $(N=350)$ & $\begin{array}{l}(N=132) \\
M=2.61(2.15)\end{array}$ & & $\begin{array}{l}(N=218) \\
M=2.30(1.75)\end{array}$ & & $\begin{array}{l}t(234.26)=1.39 p=.17^{\mathrm{c}} \\
\mathrm{CI}=[-.13, .74]\end{array}$ \\
\hline
\end{tabular}




\begin{tabular}{|c|c|c|c|c|c|}
\hline Court Site $(N=347)$ & $(N=134)$ & & $(N=213)$ & & \\
\hline 102/Old City Hall & 39 & $29.1 \%$ & 51 & $23.9 \%$ & \\
\hline Metro West & $10^{b}$ & $7.5 \%$ & 38 & $17.8 \%$ & \\
\hline Metro East & 26 & $19.4 \%$ & 46 & $21.6 \%$ & \\
\hline College Park & 25 & $18.7 \%$ & 32 & $15 \%$ & \\
\hline Metro North & 34 & $25.4 \%$ & 46 & $21.6 \%$ & $x^{2}(4,347)=8.61, p=.07$ \\
\hline Legal Status at Referral $(N=294)$ & $(N=109)$ & & $(N=185)$ & & \\
\hline Awaiting Bail & 6 & $5.5 \%$ & 8 & $4.3 \%$ & \\
\hline Awaiting Trial & 100 & $91.7 \%$ & 169 & $91.4 \%$ & \\
\hline Awaiting Sentencing & 3 & $2.8 \%$ & 8 & $4.3 \%$ & $x^{2}(2,294)=.65, p=.72$ \\
\hline
\end{tabular}

Note. $\mathrm{CI}=$ confidence interval

${ }^{\mathrm{a}}$ significantly higher proportion than expected, ${ }^{\mathrm{b}}$ significantly lower proportion than expected, ${ }^{\mathrm{c}}$ equal variances not assumed. 
Table 5

Univariate Relationships Between All Variables and Reason for Unsuccessful Diversion.

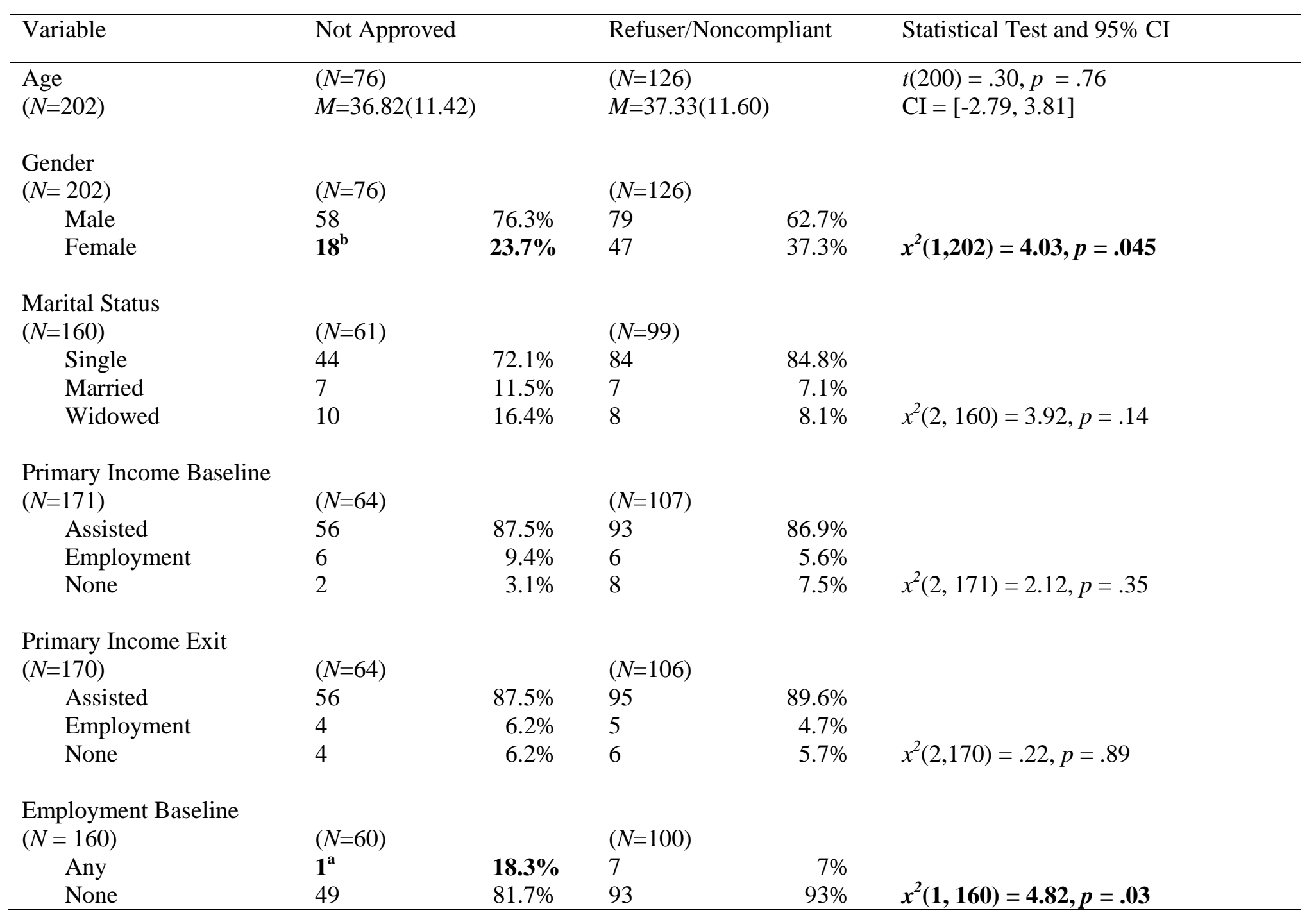




\begin{tabular}{|c|c|c|c|c|c|}
\hline $\begin{array}{l}\text { Employment Current } \\
(N=156)\end{array}$ & $(N=59)$ & & $(N=97)$ & & \\
\hline Any & $11^{\mathrm{a}}$ & $18.6 \%$ & 7 & $7.2 \%$ & \\
\hline None & 48 & $81.4 \%$ & 90 & $92.8 \%$ & $x^{2}(1,156)=4.69, p=.03$ \\
\hline $\begin{array}{l}\text { Living Situation Baseline } \\
(N=181)\end{array}$ & $(N=68)$ & & $(N=113)$ & & \\
\hline Self/Alone & 23 & $33.8 \%$ & 45 & $39.8 \%$ & \\
\hline Relatives & 20 & $29.4 \%$ & 25 & $22.1 \%$ & \\
\hline Non-Relatives & 25 & $36.8 \%$ & 43 & $38.1 \%$ & $x^{2}(2,181)=1.33, p=.51$ \\
\hline $\begin{array}{l}\text { Living Situation Exit } \\
(N=175)\end{array}$ & $(N=67)$ & & $(N=108)$ & & \\
\hline Self/Alone & 20 & $29.9 \%$ & 47 & $43.5 \%$ & \\
\hline Relatives & 27 & $40.3 \%$ & 27 & $25 \%$ & \\
\hline Non-Relatives & 20 & $29.9 \%$ & 34 & $31.5 \%$ & $x^{2}(2,175)=5.19, p=.07$ \\
\hline $\begin{array}{l}\text { Housing Type Baseline } \\
(N=186)\end{array}$ & $(N=70)$ & & $(N=116)$ & & \\
\hline Market Rent & 21 & $30 \%$ & 40 & $34.5 \%$ & \\
\hline Subsidized & 25 & $35.7 \%$ & 28 & $24.1 \%$ & \\
\hline Homeless & $9^{b}$ & $12.9 \%$ & 34 & $29.3 \%$ & \\
\hline Institutional & 15 & $21.4 \%$ & 14 & $12.1 \%$ & $x^{2}(3,186)=9.88, p=.02$ \\
\hline $\begin{array}{l}\text { Housing Type Exit } \\
(N=165)\end{array}$ & $(N=62)$ & & $(N=103)$ & & \\
\hline Market Rent & 23 & $37.1 \%$ & 35 & $34 \%$ & \\
\hline Subsidized & 26 & $41.9 \%$ & 27 & $26.2 \%$ & \\
\hline Homeless & $\mathbf{8}^{\mathbf{b}}$ & $12.9 \%$ & 33 & $32 \%$ & \\
\hline Institutional & 5 & $8.1 \%$ & 8 & $7.8 \%$ & $x^{2}(3,165)=8.79, p=.03$ \\
\hline
\end{tabular}




\begin{tabular}{|c|c|c|c|c|c|}
\hline $\begin{array}{l}\text { Primary Diagnosis } \\
(N=192)\end{array}$ & $(N=74)$ & & $(N=118)$ & & \\
\hline Psychotic & $21^{\mathrm{b}}$ & $28.4 \%$ & 67 & $56.8 \%$ & \\
\hline Mood/Anxiety & $42^{\mathrm{a}}$ & $56.8 \%$ & 37 & $31.4 \%$ & \\
\hline Personality & 1 & $1.4 \%$ & 2 & $1.7 \%$ & \\
\hline Substance Abuse & 4 & $5.4 \%$ & 3 & $2.5 \%$ & \\
\hline Other & 4 & $5.4 \%$ & 6 & $5.1 \%$ & \\
\hline None & 2 & $2.7 \%$ & 3 & $2.5 \%$ & $x^{2}(5,192)=16.21, p=.006$ \\
\hline $\begin{array}{l}\text { Any Substance Use Issues } \\
(N=192)\end{array}$ & $(N=74)$ & & $(N=118)$ & & \\
\hline Yes & 25 & $33.8 \%$ & 33 & $28 \%$ & \\
\hline No & 49 & $66.2 \%$ & 85 & $72 \%$ & $x^{2}(1,192)=.73, p=.39$ \\
\hline $\begin{array}{l}\text { Sum Clinical Needs } \\
(N=181)\end{array}$ & $\begin{array}{l}(N=67) \\
M=.63(.88)\end{array}$ & & $\begin{array}{l}(N=114) \\
M=.77(.92)\end{array}$ & & $\begin{array}{l}t(179)=1.04, p=.30 \\
\mathrm{CI}=[-.13, .42]\end{array}$ \\
\hline $\begin{array}{l}\text { Sum Psychosocial Needs } \\
(N=181)\end{array}$ & $\begin{array}{l}(N=67) \\
M=.57(.86)\end{array}$ & & $\begin{array}{l}(N=114) \\
M=.81(.99)\end{array}$ & & $\begin{array}{l}t(179)=1.66, p=.10 \\
\mathrm{CI}=[-.05, .52]\end{array}$ \\
\hline Legal Needs $(N=181)$ & $(N=67)$ & & $(N=114)$ & & \\
\hline Yes & 15 & $22.4 \%$ & 22 & $19.3 \%$ & \\
\hline No & 52 & $77.6 \%$ & 92 & $80.7 \%$ & $x^{2}(1,181)=.25, p=.62$ \\
\hline $\begin{array}{l}\text { Presenting Issues Clinical } \\
(N=200)\end{array}$ & $\begin{array}{l}(N=76) \\
M=.97(.82)\end{array}$ & & $\begin{array}{l}(N=124) \\
M=1.20(.79)\end{array}$ & & $\begin{array}{l}t(198)=1.96, p=.05 \\
C I=[-.001, .46]\end{array}$ \\
\hline Presenting Issues & $(N=76)$ & & $(N=124)$ & & $t(198)=.28, p=.78$ \\
\hline Psychosocial $(N=200)$ & $M=.74(.91)$ & & $M=.77(.93)$ & & $\mathrm{CI}=[-.23, .30]$ \\
\hline $\begin{array}{l}\text { Presenting Legal Issues } \\
(N=200)\end{array}$ & $(N=76)$ & & $(N=124)$ & & \\
\hline Yes & 74 & $97.4 \%$ & 120 & $96.8 \%$ & \\
\hline No & 2 & $2.6 \%$ & 4 & $3.2 \%$ & $x^{2}(1,200)=.06, p=.81$ \\
\hline
\end{tabular}




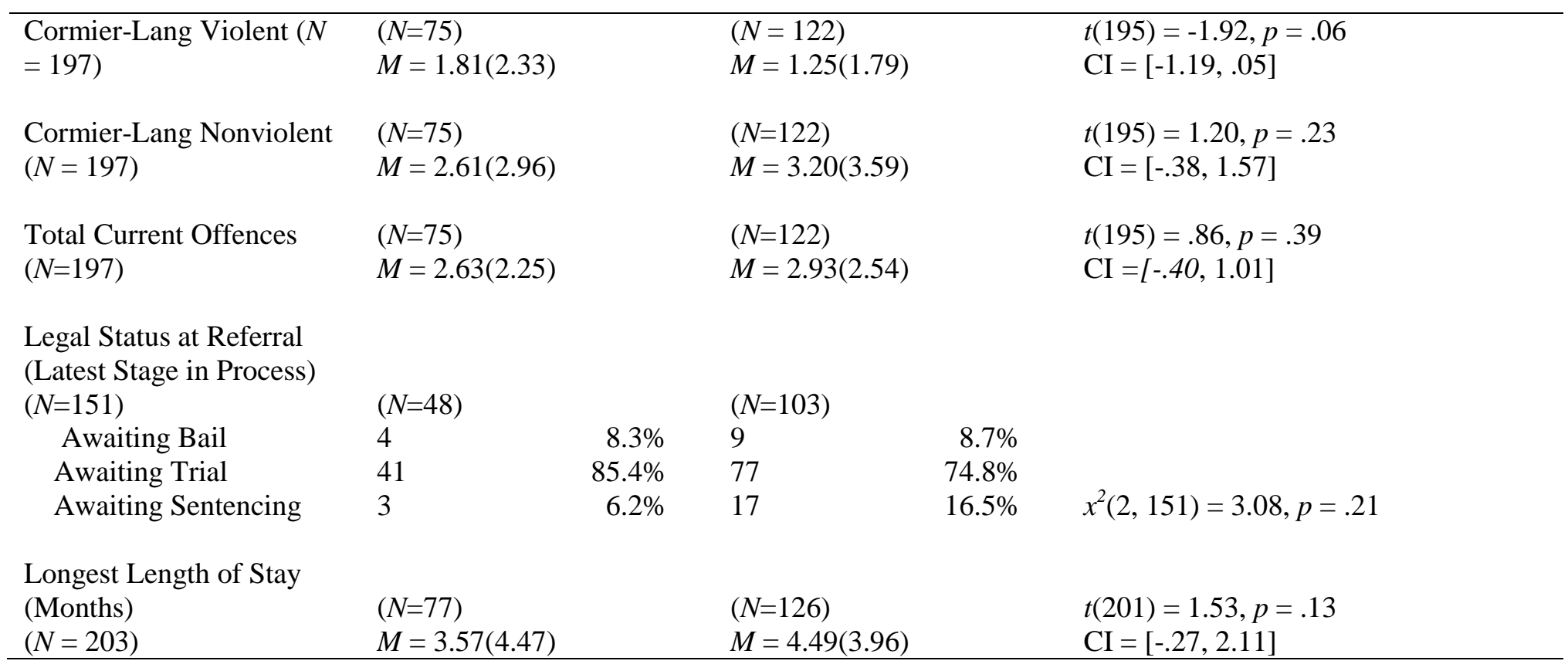

Note. $\mathrm{CI}=$ confidence interval.

${ }^{a}$ significantly higher proportion than expected, ${ }^{b}$ significantly lower proportion than expected. 
Table 6

Study 2 Logistic Regression Results from Final Block of Forced-Entry Regression Analysis.

\begin{tabular}{|c|c|c|c|}
\hline Variable & $b(S E)$ & $B$ & $95 \% \mathrm{CI}$ \\
\hline $\begin{array}{l}\text { Criminal History Composite - No } \\
\text { Criminal History vs. Criminal } \\
\text { History }\end{array}$ & $-.84(.33)^{*}$ & .43 & {$[.23, .82]$} \\
\hline $\begin{array}{l}\text { Criminal History Composite - No } \\
\text { Criminal History vs. Missing } \\
\text { Criminal History }\end{array}$ & $-.92(.32)^{* *}$ & .40 & {$[.21, .74]$} \\
\hline $\begin{array}{l}\text { Marital Status - Single vs. } \\
\text { Married }\end{array}$ & $.80(.39)^{*}$ & 2.23 & {$[1.04,4.77]$} \\
\hline Legal Needs & $-.97(.35)^{* *}$ & .38 & {$[.19, .75]$} \\
\hline Clinical Needs Total & $-.30(.15)^{*}$ & .74 & {$[.56, .99]$} \\
\hline Longest LOS (Months) & $.19(.03)^{* * *}$ & 1.21 & {$[1.14,1.30]$} \\
\hline $\begin{array}{l}\text { Court Site }-102 / \mathrm{OCH} \text { vs. Metro } \\
\text { East }\end{array}$ & $-1.22(.41)^{* *}$ & .30 & {$[.13, .66]$} \\
\hline $\begin{array}{l}\text { Court Site }-102 / \mathrm{OCH} \text { vs. College } \\
\text { Park }\end{array}$ & $.68(.33)^{*}$ & 1.98 & {$[1.03,3.80]$} \\
\hline
\end{tabular}

Note. $N=599 ; \mathrm{CI}=$ confidence interval; Model chi-square $=x^{2}(36, N=599)=150.36, p<.001$

$*_{p}<.05, * * p<.01, * * * p<.001$ 
Table 7

Study 3 Logistic Regression Results from Final Block of Model 1

\begin{tabular}{llll}
\hline Variable & $b(S E)$ & $B$ & $95 \%$ CI \\
\hline $\begin{array}{l}\text { Living Situation Baseline -living } \\
\quad \text { alone vs. living with relatives }\end{array}$ & $1.17(.55)^{*}$ & 3.21 & {$[1.09,9.48]$} \\
$\begin{array}{l}\text { Living Situation Baseline - living } \\
\quad \text { alone vs. living with non- }\end{array}$ & $.10(.43)$ & 1.10 & {$[.47,2.58]$} \\
$\quad$ relatives & & & .58 \\
$\quad \begin{array}{ll}\text { Clinical Needs Total } \\
\text { Primary Diagnosis Mood/Anxiety }\end{array}$ & $-.55(.23)^{*}$ & 3.00 & {$[.37, .91]$} \\
Longest LOS in Months & $.32(.07)^{* * *}$ & 1.38 & {$[1.37,6.55]$} \\
\hline
\end{tabular}

Note. $N=231 ; \mathrm{CI}=$ confidence interval; Model chi-square: $x^{2}(5, N=231)=46.36, p<.001$

$* p<.05, * * p<.01, * * * p<.001$ 
Table 8

Study 3 Logistic Regression Results from Final Block of Model 2

\begin{tabular}{|c|c|c|c|}
\hline Variable & $b(S E)$ & $B$ & $95 \% \mathrm{CI}$ \\
\hline $\begin{array}{l}\text { Criminal History Composite - No } \\
\text { Criminal History vs. Criminal } \\
\text { History }\end{array}$ & $-.73(.30)^{*}$ & .48 & {$[.27, .85]$} \\
\hline $\begin{array}{l}\text { Criminal History Composite - No } \\
\text { Criminal History vs. Missing } \\
\text { Criminal History }\end{array}$ & $-.65(.24) * *$ & .52 & {$[.32, .84]$} \\
\hline Age & $.01(.01)$ & 1.01 & {$[1.00,1.03]$} \\
\hline $\begin{array}{l}\text { Marital - Single vs. } \\
\text { Married/Common Law }\end{array}$ & $.63(.34)$ & 1.88 & {$[.97,3.67]$} \\
\hline $\begin{array}{l}\text { Marital - Single vs. } \\
\text { Divorced/Separated/Widowed }\end{array}$ & $.12(.34)$ & 1.13 & {$[.58,2.22]$} \\
\hline Marital - Single vs. Missing & $-.56(.39)$ & .57 & {$[.27,1.21]$} \\
\hline $\begin{array}{l}\text { Cormier-Lang Nonviolent } \\
\text { Severity Score }\end{array}$ & $-.12(.04)^{* *}$ & .89 & {$[.83, .95]$} \\
\hline $\begin{array}{l}\text { Legal Status at Referral - } \\
\text { Awaiting Bail vs. Awaiting Trial }\end{array}$ & $.55(.45)$ & 1.73 & {$[.71,4.21]$} \\
\hline $\begin{array}{l}\text { Legal Status at Referral - } \\
\text { Awaiting Bail vs. Awaiting } \\
\text { Sentencing }\end{array}$ & $.21(.57)$ & 1.24 & {$[.41,3.75]$} \\
\hline $\begin{array}{l}\text { Legal Status at Referral - } \\
\text { Awaiting Bail vs. Missing }\end{array}$ & $-.43(.49)$ & .65 & {$[.25,1.69]$} \\
\hline Legal Needs & $-.66(.28)^{*}$ & .52 & {$[.30,89]$} \\
\hline Clinical Needs Total & $-.31(.12)^{*}$ & .73 & {$[.57, .93]$} \\
\hline Longest LOS (Months) & $.18(.03)^{* * *}$ & 1.20 & {$[1.13,1.27]$} \\
\hline
\end{tabular}

Note. $N=612 ; \mathrm{CI}=$ confidence interval; Model chi-square $=x^{2}(13, N=612)=117.89, p<.001$

$* p<.05, * * p<.01, * * * p<.001$ 
Table 9

Study 3 Logistic Regression Results from Final Block of Model 3

\begin{tabular}{|c|c|c|c|}
\hline Variable & $b(S E)$ & $B$ & $95 \% \mathrm{CI}$ \\
\hline Age & $.01(.01)$ & 1.01 & {$[.99,1.04]$} \\
\hline $\begin{array}{l}\text { Cormier-Lang Nonviolent } \\
\text { Severity Score }\end{array}$ & $-.11(.04)^{* *}$ & .89 & {$[.82, .97]$} \\
\hline $\begin{array}{l}\text { Baseline Housing - Private } \\
\text { House/Market Rent vs. } \\
\text { Supported/Subsidized/Non- } \\
\text { profit }\end{array}$ & $-.25(.32)$ & .78 & {$[.42,1.46]$} \\
\hline $\begin{array}{l}\text { Baseline Housing - Private } \\
\text { House/Market Rent vs. } \\
\text { Homeless }\end{array}$ & $-.89(.39)^{*}$ & .41 & {$[.20, .86]$} \\
\hline $\begin{array}{l}\text { Baseline Housing - Private } \\
\text { House/Market Rent vs. } \\
\text { Institutional }\end{array}$ & $-.90(.39)^{*}$ & .41 & {$[.20, .87]$} \\
\hline Clinical Needs Total & $-.38(.15)^{*}$ & .68 & {$[.51, .92]$} \\
\hline Longest LOS (Months) & $.21(.04)^{* * *}$ & 1.23 & {$[1.13,1.33]$} \\
\hline
\end{tabular}

Note. $N=424 ; \mathrm{CI}=$ confidence interval; Model chi-square $=x^{2}(7, N=424)=61.30, p<.001$

$* p<.05, * * p<.01, * * * p<.001$ 
Table 10

Study 3 Logistic Regression Results from Final Block of Model 4

\begin{tabular}{|c|c|c|c|}
\hline Variable & $b(S E)$ & $B$ & $95 \% \mathrm{CI}$ \\
\hline Age & $.01(.01)$ & 1.02 & {$[1.00,1.03]$} \\
\hline $\begin{array}{l}\text { Marital Status - Single vs. } \\
\text { Married/Common } \\
\text { Law/Domestic Partner }\end{array}$ & $.62(.33)$ & 1.87 & {$[.97,3.59]$} \\
\hline $\begin{array}{l}\text { Marital Status - Single vs. } \\
\text { Divorced/Widowed/Separated }\end{array}$ & $.15(.34)$ & 1.16 & {$[.60,2.26]$} \\
\hline $\begin{array}{l}\text { Marital Status - Single vs. } \\
\text { Missing }\end{array}$ & $-.62(.37)$ & .54 & {$[.26,1.11]$} \\
\hline $\begin{array}{l}\text { Cormier-Lang Nonviolent } \\
\text { Severity Score }\end{array}$ & $-.12(.04) * * *(\mathrm{P}=.001)$ & .88 & {$[.82, .95]$} \\
\hline $\begin{array}{l}\text { Legal Status at Referral - } \\
\text { Awaiting Bail vs. Awaiting Trial }\end{array}$ & $.74(.44)$ & 2.10 & {$[.88,4.99]$} \\
\hline $\begin{array}{l}\text { Legal Status at Referral- } \\
\text { Awaiting Bail vs. Awaiting } \\
\text { Sentencing }\end{array}$ & $.31(.54)$ & 1.36 & {$[.47,3.95]$} \\
\hline $\begin{array}{l}\text { Legal Status at Referral - } \\
\text { Awaiting Bail vs. Missing }\end{array}$ & $-.30(.47)$ & .74 & {$[.29,1.87]$} \\
\hline Clinical Needs Total & $-.39(.12)^{* *}$ & .68 & {$[.53, .86]$} \\
\hline Longest LOS (Months) & $.18(.03) * * *$ & 1.19 & {$[1.12,1.27]$} \\
\hline
\end{tabular}

Note. $N=612 ; \mathrm{CI}=$ confidence interval; Model chi-square $=x^{2}(10, N=612)=103.56, p<.001$

$* p<.05, * * p<.01, * * * p<.001$ 
Table 11

Study 3 Area Under the Curve Statistics for all Multivariate Models.

\begin{tabular}{llll}
\hline Model & AUC & SE & $95 \%$ CI \\
\hline Model 1 & $.70^{* * *}$ & .02 & $.67, .74$ \\
Model 2 & $.76^{* * *}$ & .02 & $.73, .80$ \\
Model 3 & $.73^{* * *}$ & .02 & $.69, .76$ \\
Model 4 & $.75^{* * *}$ & .02 & $.71, .78$ \\
\hline
\end{tabular}

Note. $\mathrm{CI}=$ confidence interval

$* * * p<.001$ 
Table 12

Study 4 Intercorrelations for Checklist Variables.

\begin{tabular}{rllcl}
\hline Variable & 1 & 2 & 3 & 4 \\
\hline 1. & $\begin{array}{l}\text { Clinical Needs }- \\
\text { Checklist }\end{array}$ & - & & \\
2. $\begin{array}{l}\text { Prior Criminal } \\
\text { History - Missing } \\
\text { as Category }\end{array}$ & $.08^{*}$ & - & - \\
3. & Legal Needs & $.22^{* *}$ & -.01 & \\
4. $\begin{array}{l}\text { Cormier-Lang } \\
\text { Nonviolent } \\
\text { Severity Score }\end{array}$ & .07 & $.08^{*}$ & -.03 & - \\
\hline
\end{tabular}

$* p<.05, * * p<.01$ 
Table 13

Study 4 Variable Weighting for Diversion Success Checklist.

\begin{tabular}{|c|c|c|c|c|}
\hline Predictor & Checklist Item & Unweighted & Ranked & Beta Weighted \\
\hline Criminal History & $\begin{array}{l}\text { Does client have a criminal } \\
\text { history or a missing } \\
\text { criminal history? }\end{array}$ & $\begin{array}{l}\text { Yes }=0 \\
\text { No }=1\end{array}$ & $\begin{array}{l}\text { Yes }=0^{\mathrm{a}} \\
\mathrm{No}=4\end{array}$ & $\begin{array}{l}\text { Yes }=0^{\mathrm{a}} \\
\mathrm{No}=6\end{array}$ \\
\hline Legal Needs & $\begin{array}{l}\text { Does client have additional } \\
\text { legal needs? }\end{array}$ & $\begin{array}{l}\text { Yes }=0 \\
\text { No }=1\end{array}$ & $\begin{array}{l}\text { Yes }=0 \\
\text { No }=3\end{array}$ & $\begin{array}{l}\text { Yes }=0 \\
\text { No }=6\end{array}$ \\
\hline Clinical Needs & $\begin{array}{l}\text { Does client need a } \\
\text { physician or psychiatrist? }\end{array}$ & $\begin{array}{l}\text { Yes (either) }=0 \\
\text { No }=1\end{array}$ & $\begin{array}{l}\text { Yes (either) }=0 \\
\text { No }=2\end{array}$ & $\begin{array}{l}\text { Yes (either) }=0 \\
\text { No }=3\end{array}$ \\
\hline $\begin{array}{l}\text { Cormier-Lang Nonviolent } \\
\text { Severity Score for Index } \\
\text { Offences }\end{array}$ & $\begin{array}{l}\text { What is the client's } \\
\text { nonviolent Cormier-Lang } \\
\text { severity score for the index } \\
\text { offences? }\end{array}$ & $\begin{array}{l}0-2=1 \\
3+=0\end{array}$ & $\begin{array}{l}0-2=1 \\
3+=0\end{array}$ & $\begin{array}{l}0-2=1 \\
3+=0\end{array}$ \\
\hline Total Possible Score & & 4 & 10 & 16 \\
\hline
\end{tabular}

"The relative ranking and beta weighting for the criminal history variable was determined from the average of the betas from the regression contrasts for "no criminal history vs. criminal history" and "no criminal history vs. missing criminal history". 
Table 14

Study 4 Area Under the Curve Statistics for Checklist Scores, Construction Sample.

\begin{tabular}{llll}
\hline Checklist Weighting & AUC & $S E$ & $95 \%$ CI \\
\hline Unweighted & $.65^{* * *}$ & .03 & {$[.59, .71]$} \\
Ranked & $.66^{* * *}$ & .03 & {$[.61, .72]$} \\
Beta Weighted & $.66^{* * *}$ & .03 & {$[.60, .72]$} \\
& & .03 & {$[.54, .66]$} \\
Unweighted (No & $.60^{* *}$ & & \\
$\quad$ Criminal History) & & .03 & {$[.54, .67]$} \\
Ranked (No Criminal & $.60^{* *}$ & & \\
$\quad$ History) & & .03 & {$[.54, .66]$} \\
Beta Weighted (No & $.60^{* *}$ & & \\
$\quad$ Criminal History) & & &
\end{tabular}

Note. $\mathrm{CI}=$ confidence interval.

$* * p<.01 ; * * * p<.001$ 
Table 15

Study 4 Area Under the Curve Statistics for Checklist Scores, Reliability Sample.

\begin{tabular}{llll}
\hline Checklist Weighting & AUC & $S E$ & $95 \%$ CI \\
\hline Unweighted & $.63^{* * *}$ & .04 & {$[.56, .70]$} \\
Ranked & $.64^{* * *}$ & .03 & {$[.57, .71]$} \\
Beta Weighted & $.64^{* * *}$ & .03 & {$[.57, .71]$} \\
& & .04 & {$[.54, .68]$} \\
Unweighted (No & $.61^{* *}$ & & {$[.54, .68]$} \\
$\quad$ Criminal History) & & .04 & {$[.54, .68]$} \\
$\begin{array}{l}\text { Ranked (No Criminal } \\
\quad \text { History) }\end{array}$ & $.61^{* *}$ & & \\
Beta Weighted (No & $.61^{* *}$ & .04 & \\
$\quad$ Criminal History) & & &
\end{tabular}

Note. $\mathrm{CI}=$ confidence interval.

$* * p<.01 ; * * * \quad p<.001$ 
Table 16

Study 4 Probability Distribution for Checklist Scores in Construction Sample, Ranked Weighting.

\begin{tabular}{lccc}
\hline Checklist Score & $n$ (Successful) & $n$ (Unsuccessful) & Percentage Successful \\
\hline 0 & 7 & 11 & $38.9 \%$ \\
1 & 10 & 13 & $43.5 \%$ \\
2 & 6 & 3 & $66.7 \%$ \\
3 & 18 & 20 & $47.4 \%$ \\
4 & 15 & 14 & $51.7 \%$ \\
5 & 34 & 26 & $56.7 \%$ \\
6 & 54 & 27 & $66.7 \%$ \\
7 & 10 & 6 & $62.5 \%$ \\
8 & 11 & 1 & $91.7 \%$ \\
9 & 18 & 3 & $85.7 \%$ \\
10 & 42 & 9 & $82.4 \%$ \\
\hline
\end{tabular}

Note. $N=358$ as 3 cases were missing. 
Table 17

Study 4 Probability Distribution for Checklist Scores in Reliability Sample, Ranked Weighting.

\begin{tabular}{lccc}
\hline Checklist Score & $n$ (Successful) & $n$ (Unsuccessful & Percentage Successful \\
\hline 0 & 3 & 9 & $25 \%$ \\
1 & 11 & 13 & $45.8 \%$ \\
2 & 1 & 1 & $50 \%$ \\
3 & 22 & 10 & $68.8 \%$ \\
4 & 24 & 7 & $77.4 \%$ \\
5 & 44 & 17 & $72.1 \%$ \\
6 & 76 & 20 & $79.2 \%$ \\
7 & 13 & 1 & $92.9 \%$ \\
8 & 16 & 4 & $80 \%$ \\
9 & 15 & 3 & $83.3 \%$ \\
10 & 33 & 7 & $82.5 \%$ \\
\hline
\end{tabular}

Note. $N=350$ as 7 values were missing. 
Table 18

Study 4 Collapsed Probability Distributions for Checklist Construction Sample, Ranked Scoring.

\begin{tabular}{lllll}
\hline Category & Scores & $n$ (Successful) & $n$ (Unsuccessful) & Percentage Successful \\
\hline Low Success & $0,1,2,3$ & $\mathbf{4 1}^{\mathbf{b}}$ & $\mathbf{4 7}^{\mathbf{a}}$ & $46.6 \%$ \\
Moderate Success & $4,5,6,7$ & 113 & 73 & $60.8 \%$ \\
High Success & $8,9,10$ & $\mathbf{7 1}^{\mathbf{a}}$ & $\mathbf{1 3}^{\mathbf{b}}$ & $84.5 \%$ \\
\hline
\end{tabular}

Note. $x^{2}(2,358)=27.14, p<.001$

${ }^{a}$ significantly higher proportion than expected, ${ }^{b}$ significantly lower proportion than expected 
Table 19

Study 4 Collapsed Probability Distributions for Checklist Reliability Sample, Ranked Weighting.

\begin{tabular}{lllll}
\hline Category & Scores & $n$ (Successful) & $n$ (Unsuccessful) & Percentage Successful \\
\hline Low Success & $0-3$ & $\mathbf{3 7}^{\mathbf{b}}$ & $\mathbf{3 3}^{\mathbf{a}}$ & $52.9 \%$ \\
Moderate Success & $4-7$ & 157 & 45 & $77.7 \%$ \\
High Success & $8-10$ & 64 & 14 & $82.1 \%$ \\
\hline
\end{tabular}

Note. $x^{2}(2,350)=20.19, p<.001$

a significantly higher proportion than expected, ${ }^{\mathrm{b}}$ significantly lower proportion than expected. 
Appendix

\begin{tabular}{|c|c|c|c|}
\hline Variable & Original Categories & Recoded Categories & Subsumed Under Category \\
\hline \multirow{10}{*}{$\begin{array}{l}\text { Primary } \\
\text { Income }\end{array}$} & ODSP/FBA & Assisted & ODSP/FBA \\
\hline & OWA/GWA & & OWA/GWA \\
\hline & Family & Employment & Employment Insurance \\
\hline & Employment & & Disability Assistance \\
\hline & Other & & Family \\
\hline & None & & CPP/Pension \\
\hline & Unknown/Declined & & \\
\hline & CPP/Pension & Employment & Employment \\
\hline & Employment Insurance & & \\
\hline & Disability Assistance & None & None \\
\hline \multirow{9}{*}{$\begin{array}{l}\text { Living } \\
\text { Situation }\end{array}$} & Alone & Alone & \\
\hline & Spouse/Partner & & \\
\hline & Spouse/Partner and others & Relatives & Spouse/Partner \\
\hline & Children & & Spouse/Partner/Others \\
\hline & Parents & & Children \\
\hline & Relatives & & Parents \\
\hline & Non-Relatives & & Relatives \\
\hline & Unknown/Declined & & \\
\hline & & Non-Relatives & Non-Relatives \\
\hline \multirow{8}{*}{$\begin{array}{l}\text { Baseline } \\
\text { Housing }\end{array}$} & Rooming/Boarding & Private House/ Market Rent & Private house/Apartment \\
\hline & Other & & Retirement Home/Seniors Residence \\
\hline & Unknown/Declined & & \\
\hline & Private House/Apt & Supported/Nonprofit/ Subsidized & Rooming/Boarding \\
\hline & No Fixed Address & & Approved Home/Home for special care \\
\hline & Approved Home/Home for & & Supportive housing/Congregate living \\
\hline & Special Care & & \\
\hline & Correctional/Probational Facility & & Supportive living/assisted living \\
\hline
\end{tabular}




\begin{tabular}{|c|c|c|c|}
\hline & $\begin{array}{l}\text { General Hospital } \\
\text { Psychiatric Hospital } \\
\text { Domiciliary Hostel } \\
\text { Other Specialty Hospital } \\
\text { Hostel/shelter } \\
\text { Long Term Care/Nursing Home } \\
\text { Municipal Nonprofit housing } \\
\text { Private Nonprofit housing } \\
\text { Private House/ Apt/Subsidized } \\
\text { Retirement home/seniors } \\
\text { residence } \\
\text { Supportive housing - } \\
\text { Congregate Living } \\
\text { Supportive Housing - Assisted } \\
\text { Living }\end{array}$ & $\begin{array}{l}\text { No Fixed Address } \\
\text { Institutional }\end{array}$ & $\begin{array}{l}\text { Private House/Apt/Subsidized } \\
\text { Municipal Nonprofit housing } \\
\text { Private Nonprofit housing } \\
\text { Domiciliary Hostel } \\
\text { Hostel/Shelter } \\
\text { No Fixed Address } \\
\text { Long Term Care/Nursing Home } \\
\text { General Hospital } \\
\text { Psychiatric Hospital } \\
\text { Correctional/Probational Facility } \\
\text { Other Specialty Hospital } \\
\text { Correctional/Probational } \\
\text { Psychiatric Hospital }\end{array}$ \\
\hline Employment & $\begin{array}{l}\text { Independent/competitive } \\
\text { Assisted/Supported } \\
\text { Alternative Business } \\
\text { Sheltered Workshop } \\
\text { No-Paid work experience } \\
\text { No employment - Other activity } \\
\text { Casual/Sporadic } \\
\text { No employment of Any Kind } \\
\text { Unknown/Declined }\end{array}$ & Some Type of Employment & $\begin{array}{l}\text { Independent/competitive } \\
\text { Assisted/Supported } \\
\text { Alternative Business } \\
\text { Sheltered Workshop } \\
\text { No-paid work experience } \\
\text { Casual Sporadic }\end{array}$ \\
\hline
\end{tabular}




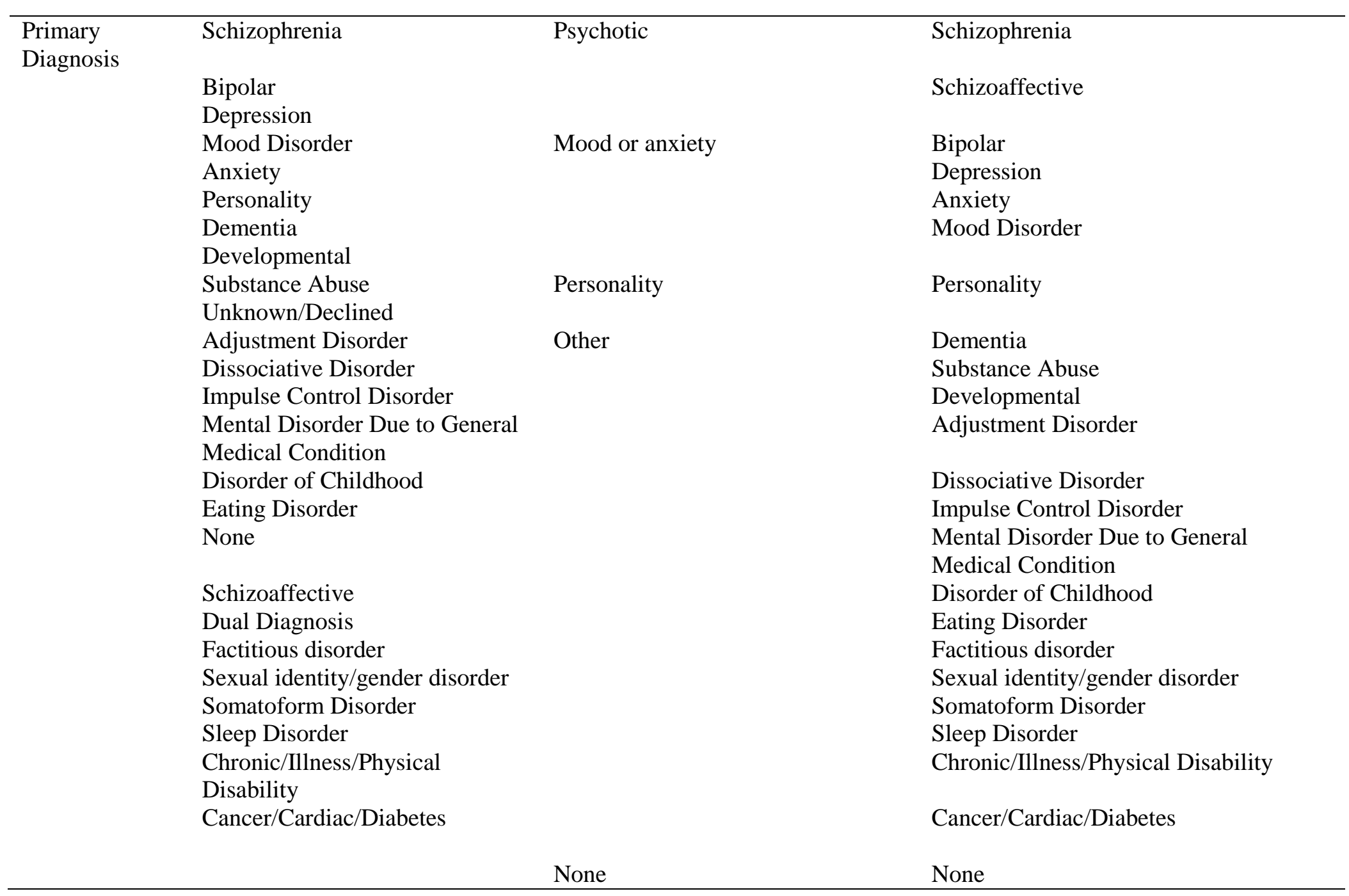




\begin{tabular}{|c|c|c|c|}
\hline \multirow{14}{*}{$\begin{array}{l}\text { Presenting } \\
\text { Issues }\end{array}$} & ThreatOthers/Suicide & Clinical & ThreatOthers/Suicide \\
\hline & Specific Symptoms Significant & & Specific Symptoms Significant Mental \\
\hline & Mental Illness & & Illness \\
\hline & Physical or Sexual Abuse & & Physical Sexual Abuse \\
\hline & Educational & & Substance abuse \\
\hline & $\begin{array}{l}\text { Occupational/Employment } \\
\text { /Vocational }\end{array}$ & & \\
\hline & Housing & Psychosocial & Assistance with Daily Living \\
\hline & Financial & & Financial \\
\hline & Substance abuse & & Relationships \\
\hline & Legal & & Housing \\
\hline & Relationships & & $\begin{array}{l}\text { Occupational/Employment/ } \\
\text { Vocational }\end{array}$ \\
\hline & Assistance with Daily Living & & \\
\hline & Other & Legal & Legal \\
\hline & No Issues & & \\
\hline \multirow[t]{9}{*}{ Marital Status } & Single & Single & Single \\
\hline & Married & & \\
\hline & Common Law & Married & Married \\
\hline & Divorced & & Common Law \\
\hline & Separated & & Domestic Partner \\
\hline & Widowed & & \\
\hline & Domestic Partner & Previously Married & Divorced \\
\hline & Unknown/Declined & & Separated \\
\hline & & & Widowed \\
\hline \multirow[t]{8}{*}{ Needs } & Psychiatrist & Clinical & Psychiatrist \\
\hline & Physician & & Physician \\
\hline & Substance Abuse Services & & Substance Abuse Services \\
\hline & Rehabilitation & & Rehabilitation \\
\hline & Assertive Community Treatment & & Assertive Community Treatment Team \\
\hline & Team & & \\
\hline & Housing - Shelter & & \\
\hline & Housing - Safebeds & Psychosocial & Housing - Shelter \\
\hline
\end{tabular}




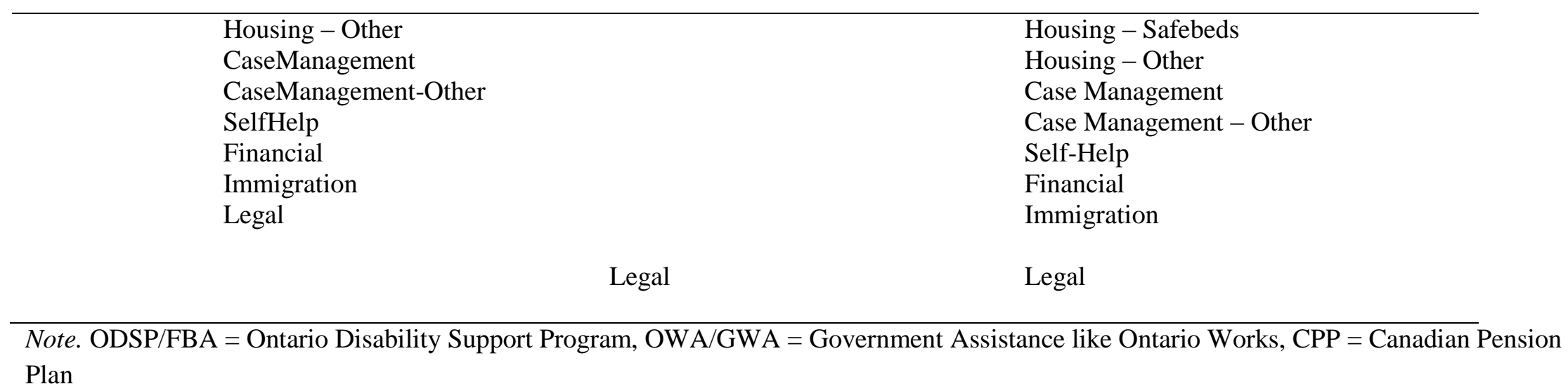




\section{References}

Barber-Rioja, V., Dewey, L., Kopelovich, S., \& Kucharski, L.T. (2012). The Utility of the HCR20 and the PCL:SV in the prediction of diversion noncompliance and reincarceration in diversion programs. Criminal Justice and Behavior, 39(4), 475-492.

Bennell, C. (2005). Improving police decision-making: General principles and practical applications of receiver operating characteristics analysis. Applied Cognitive Psychology, 19(9), 1157-1175.

Bonta, J., Blais, J., \& Wilson, H.A. (2014). A theoretically informed meta-analysis of the risk for general and violent recidivism for mentally disordered offenders. Aggression and Violent Behavior, 19(3), 278-287.

Bonta, J., Law, M., \& Hanson, K. (1998). The prediction of criminal and violent recidivism among mentally disordered offenders: A meta-analysis. Psychological Bulletin, 123(2), 123 142.

Burns, P.J., Hiday, V.A., \& Ray, B. (2013). Effectiveness 2 years postexit of a recently established mental health court. American Behavioral Scientist, 57(2), 189-208.

Case, B., Steadman, H.J., Dupuis, S.A., \& Morris, L.S. (2009). Who succeeds in jail diversion programs for persons with mental illness? A multi-site study. Behavioral Sciences and the Law, 27(5), 661-674.

Criminal Code (R.S.C., 1985, c. C-46, s. 16), Retrieved from http://laws-

lois.justice.gc.ca/eng/acts/C-46/page-5.html

Derogatis, L.R. (1983). SCL-90-R administration, scoring, and procedures manual - II. Towson, M.D: Clinical Psychometric Research. 
Fischer, S.N., Shinn, M., Shrout, P., \& Tsemberis, S. (2008). Homelessness, mental illness, and criminal activity: Examining patterns over time. American Journal of Community Psychology, 42(3-4), 251-365.

First, M.B., Spitzer, R,L., Gibbon, M., \& Williams, J.B.W. (1997). Structured clinical interview for DSM-IV Axis I disorders (SCID-I): Clinical version. Washington, DC: American Psychiatric Press.

Hartford, K., Heslop, L., Stitt, L., \& Hoch, J.S. (2005). Design of an algorithm to identify persons with mental illness in a police administrative database. International Journal of Law and Psychiatry, 28(1), 1-11.

Hart, S. D., Cox, D. N., \& Hare, R. D. (1995). The Hare Psychopathy Checklist: Screening Version (PCL:SV). Toronto, Ontario, Canada: Multi-Health Systems.

Hiday, V.A., Ray, B., \& Wales, H.W. (2014).Predictors of mental health court graduation. Psychology, Public Policy, and Law, 20(2), 191-199.

Hiday, V.A., Wales, H.W., \& Ray, B. (2013). Effectiveness of a short-term mental health court: Criminal recidivism one year postexit. Law and Human Behavior, 37(6), 401-411.

Hughes, D., Steadman, H.J., Case, B., Griffin, P.A., \& Leff, H.S. (2012). A simulation modeling approach for planning and costing jail diversion programs for persons with mental illness. Criminal Justice and Behavior, 39(4), 434-446.

Keator, K.J., Callahan, L., Steadman, H.J., \& Vesselinov, R. (2013). The impact of treatment on the public safety outcomes of mental health court participants. American Behavioral Scientist, 57(2), 231-243. 
Lange, S., Rehm, J., \& Popova, S. (2011). The effectiveness of criminal justice diversion initiatives in North America: A systematic literature review. International Journal of Forensic Mental Health, 10(3), 200-214.

MedCalc Software. (2008). MedCalc for Windows, Version 9.2.1.0. Mariakerke, Belgium.

Mental Health Commission of Canada. (2012). Changing directions, changing lives: The mental health strategy for Canada [Summary]. Retrieved from http://strategy.mentalhealthcommission.ca/pdf/strategy-summary-en.pdf

Millon, T. (1994). Millon clinical multiaxial inventory-III manual. Minneapolis, MN: National Computer Services.

Moore, M.E., \& Hiday, V.A. (2006). Mental health court outcomes: A comparison of re-arrest and re-arrest severity between mental health court and traditional court participants. Law and Human Behavior, 30(6), 659-674.

Morgan, R.D., Fisher, W.H., Duan, N., Mandracchia, J.T., \& Murray, D. (2009). Prevalence of criminal thinking among state prison inmates with serious mental illness. Law and Human Behavior, 34(4), 324-336.

Naples, M., Morris, L.S., \& Steadman, H.J. (2007). Factors in disproportionate representation among persons recommended by programs and accepted by courts for jail diversion. Psychiatric Services, 58(8), 1095-1101.

Naples, M., \& Steadman, H.J. (2003). Can persons with co-occurring disorders and violent charges be successfully diverted? International Journal of Forensic Mental Health, 2(2), 137-143. 
Ontario Ministry of the Attorney General: Criminal Law Division. (2005). Practice memorandum on diversion (PM [2005] No. 22). Retrieved from

http://www.hsjcc.on.ca/Resource\%20Library/Mental\%20Health\%20Reports/Ontario\%20MAG\% 20Practice\%20Memorandum\%20-

\%20Mental\%20Illness\%20or\%20Developmental\%20Disability\%20Diversion\%20-\%202006.pdf

Osher, F.C., \& Steadman, H.J. (2007). Adapting evidence-based practices for persons with mental illness involved with the criminal justice system. Psychiatric Services, 58(11), 14721478.

Overall, J., \& Gorham, D. (1988). The brief psychiatric rating scale (BPRS): Recent developments in ascertainment and scaling. Psychopharmacology Bulletin, 24, 97-99.

Pokorny, D., Miller, B.A., \& Kaplan, H.B. (1972). The brief MAST: A shortened version of the Michigan Alcoholism Screening Test. American Journal of Psychiatry, 129(3), 118-121.

Public Safety Canada. (2009). Corrections and Conditional Release Statistical Overview: 2009. (Report No. PS1-3/2009E). Ottawa, ON: Public Safety Canada.

Public Safety Canada. (2013). Corrections and Conditional Release Statistical Overview: 2013. (Report No. PS1-3/2013E). Ottawa, ON: Public Safety Canada.

Quinsey, V.L., Harris, G. T., Rice, M. E., \& Cormier, C.A. (2006). Violent offenders: Appraising and Managing Risk (2 ${ }^{\text {nd }}$ ed.). Washington DC: American Psychological Association.

Ryan, S., Brown, C.K., \& Watanabe-Galloway, S. (2010). Toward successful postbooking diversion: What are the next steps? Psychiatric Services, 61(5), 469-477.

Salem, L., Crocker, A. G., Charette, Y., Seto, M. C., Nicholls, T., \& Côté, G. (2014, revise \& resubmit). The influence of intermediary housing on the recidivism patterns of individuals found not criminally responsible on account of mental disorder. Manuscript under review. 
Sheldon, C.T., Aubry, T.D., Arboleda-Florez, J., Wasylenki, D., \& Goering, P.N. (2006). Social disadvantage, mental illness and predictors of legal involvement. International Journal of Law and Psychiatry, 29(3), 249-256.

Simourd, D. J. (1997). The Criminal Sentiments Scale-Modified and Pride in Delinquency Scale: Psychometric properties and construct validity of two measures of criminal attitudes. Criminal Justice and Behavior, 24(1), 52-70.

Simourd, D.J., \& Van De Ven, J. (1999). Assessment of criminal attitudes: Criterion-related validity of the criminal sentiments scale-modified and pride in delinquency scale. Criminal Justice and Behavior, 26(1), 90-106.

Sirotich, F. (2008). Correlates of crime and violence among persons with mental disorder: An evidence-based review. Brief Treatment and Crisis Intervention, 8(2), 171-194.

Sirotich, F. (2009). The criminal justice outcomes of jail diversion programs for persons with mental illness: A review of the evidence. The Journal of the American Academy of Psychiatry and Law, 37(4), 461-472.

Steadman, H.J., Cocozza, J., \& Veysey, B.M. (1999). Comparing outcomes for diverted and nondiverted jail detainees with mental illness. Law and Human Behavior, 23(6), 615-627.

Steadman, H.J., \& Naples, M. (2005). Assessing the effectiveness of jail diversion programs for persons with serious mental illness and co-occurring substance use disorders. Behavioral Sciences and the Law, 23(2), 163-170.

Steadman, H.J., Morris, S.M., \& Dennis, D.L. (1995). The diversion of mentally ill persons from jail to community-based services: A profile of programs. American Journal of Public Health, 85(12), 1630-1635. 
Steadman, H.J., Redlich, A.D., Callahan, L., Robbins, P.C., \& Vesselinov, R. (2011). Effect of mental health courts on arrests and jail days: A multisite study. Archives of General Psychiatry, 68(2), 167-172.

Steadman, H.J., Redlich, A.D., Griffin, P., Petrila, J., \& Monahan, J. (2005). From referral to disposition: Case processing in seven mental health courts. Behavioral Sciences and the Law, 23(2), 1-12.

Swets, J.A. (1988). Measuring the accuracy of diagnostic systems. Science, 240, 1285-1293.

Tabachnik, B.G., \& Fidell, L.S. (2007). Using multivariate statistics, $5^{\text {th }}$ ed. Boston, MA: Allyn \& Bacon/Pearson Education.

The Mental Health Court Support Consortium. (2005). Mental health court support policies and procedures, $1^{\text {st }}$ ed. Unpublished Manuscript.

Walters, G. D. (2006). The Psychological Inventory of Criminal Thinking Styles (PICTS) professional manual. Allentown, PA: Center for Lifestyle Studies.

Webster, C. D., Douglas, K. S., Eaves, D., \& Hart, S. D. (1997). HCR-20. Assessing the risk of violence. Version 2. Vancouver, Canada: Simon Fraser University and Forensic Psychiatric Services Commission of British Columbia.

Wormith, J. S., \& Andrews, D. A. (1984). Criminal sentiments and criminal behavior: A construct validation. Ottawa: Solicitor General Canada. 